\title{
Root growth, water uptake, and sap flow of winter wheat in response to different soil water conditions
}

\author{
Gaochao Cai ${ }^{1}$, Jan Vanderborght ${ }^{1}$, Matthias Langensiepen ${ }^{2}$, Andrea Schnepf ${ }^{1}$, Hubert Hüging ${ }^{2}$, and \\ Harry Vereecken ${ }^{1}$ \\ ${ }^{1}$ Agrosphere, Institute of Bio- and Geosciences (IBG-3), Forschungszentrum Jülich GmbH, 52428 Jülich, Germany \\ ${ }^{2}$ Institute of Crop Science and Resource Conservation, Faculty of Agriculture, University of Bonn, \\ Katzenburgweg 5, 53115 Bonn, Germany \\ Correspondence: Gaochao Cai (gaochao.cai@gmail.com)
}

Received: 4 December 2017 - Discussion started: 11 December 2017

Revised: 16 March 2018 - Accepted: 24 March 2018 - Published: 23 April 2018

\begin{abstract}
How much water can be taken up by roots and how this depends on the root and water distributions in the root zone are important questions that need to be answered to describe water fluxes in the soil-plant-atmosphere system. Physically based root water uptake (RWU) models that relate RWU to transpiration, root density, and water potential distributions have been developed but used or tested far less. This study aims at evaluating the simulated RWU of winter wheat using the empirical Feddes-Jarvis (FJ) model and the physically based Couvreur (C) model for different soil water conditions and soil textures compared to sap flow measurements. Soil water content (SWC), water potential, and root development were monitored noninvasively at six soil depths in two rhizotron facilities that were constructed in two soil textures: stony vs. silty, with each of three water treatments: sheltered, rainfed, and irrigated. Soil and root parameters of the two models were derived from inverse modeling and simulated RWU was compared with sap flow measurements for validation. The different soil types and water treatments resulted in different crop biomass, root densities, and root distributions with depth. The two models simulated the lowest RWU in the sheltered plot of the stony soil where RWU was also lower than the potential RWU. In the silty soil, simulated RWU was equal to the potential uptake for all treatments. The variation of simulated RWU among the different plots agreed well with measured sap flow but the $\mathrm{C}$ model predicted the ratios of the transpiration fluxes in the two soil types slightly better than the FJ model. The root hydraulic parameters of the $\mathrm{C}$ model could be constrained by the field data but not the water stress parameters of the FJ model. This
\end{abstract}

was attributed to differences in root densities between the different soils and treatments which are accounted for by the C model, whereas the FJ model only considers normalized root densities. The impact of differences in root density on RWU could be accounted for directly by the physically based RWU model but not by empirical models that use normalized root density functions.

\section{Introduction}

Root water uptake (RWU) is a vital process for plant functioning since it conditions nutrient transport and balances transpiration. Estimations of RWU are needed to make predictions of crop water use, to assess water and nutrient use efficiency as a function of root architecture and environmental controls, and to design efficient water and nutrient resource management in agricultural practices (Molz, 1981). However, quantifying RWU for water and nutrient management in different regions and climates continues to be a challenge due to the lack of knowledge of key RWU parameters and appropriate description of the RWU process (Vereecken et al., 2016). Typically, RWU is estimated from the transpiration demand, which is calculated from the canopy energy balance under the assumption that the crop is well watered. Different soil water balance models have been developed that allow RWU to be estimated using different parameterizations of the root system and water uptake mechanisms. However, the availability of field-plot-scale experiments in different soil 
textures and for different soil water regimes that are needed to validate and improve these models is very limited.

In many soil water balance models that are used to predict RWU, the Richards equation is used for calculating water flow in unsaturated soils and a sink term is defined that describes RWU:

$$
\frac{\partial \theta}{\partial t}=\nabla(K(h) \nabla(h+z))-S,
$$

where $\theta$ represents the volumetric soil water content (SWC) $\left(\mathrm{L}^{3} \mathrm{~L}^{-3}\right), t$ time $(\mathrm{T}), K$ the soil hydraulic conductivity $\left(\mathrm{LT}^{-1}\right), h$ the soil water pressure head (SWP) (L), $z$ the elevation (L), and $S$ the sink term $\left(\mathrm{L}^{3} \mathrm{~L}^{-3} \mathrm{~T}^{-1}\right)$, defined as the volume of water removed from a unit volume of soil due to root extraction. A popular macroscopic RWU model that has been used to quantify the sink term is the Feddes model (Feddes et al., 1976) because of its simplicity and low data requirement (Skaggs et al., 2006; Luo et al., 2003; Peters et al., 2017). It uses the normalized root length density distribution and stress functions to determine the distribution of the sink term in the root zone. Piecewise linear stress functions define how the sink term at one location in the root zone is reduced as a function of the SWP, and this function depends in turn on the potential transpiration rate. This model was refined later to the Feddes-Jarvis model by adding a factor to account for increased water uptake, i.e., uptake compensation, from moister soil layers when uptake from drier layers is reduced (Jarvis, 1989; Šimůnek and Hopmans, 2009).

Besides transpirational demand and soil water pressure head (SWP), RWU is also influenced by root hydraulic properties (i.e., root hydraulic conductance) which may vary over time due to root development and growth (Doussan et al., 1998; Steudle, 2000; Javaux et al., 2008). Root hydraulic properties determine the resistance to water flow within the plant and define the water potential losses along the sap flow from the roots to the shoot and the leaves (Bechmann et al., 2014). The relation between soil water and leaf water potentials and sap flow depends on root hydraulic properties, which therefore should be considered in RWU models (Vereecken et al., 2015; Vadez, 2014). Physically based macroscopic RWU models were developed that describe water fluxes in the soil-root (or soil-root-plant) system based on water potentials and conductivities or conductances of the soil and the root system. Nimah and Hanks (1973) characterized water uptake as a function of root density, axial root conductance, and water potential at the root collar. Heinen (2001) considered root hydraulic properties and water pressure head at the root-soil interface in the RWU model but without considering water uptake compensation. Van Lier et al. (2008) developed a 1-D water flow model in which the RWU rate was a function of root surface water potential and root radius. This model considered implicitly lateral flow from the soil to the root with an implicit compensation mechanism but did not include the information about axial root hydraulic conductances.
In order to present a mechanistic description of the RWU process that contains physically defined parameters, Couvreur et al. (2012) developed a 3-D model based on the approach of root system hydraulic architecture (Doussan et al., 2006; Javaux et al., 2008). In this model, RWU is dependent on root system hydraulic conductance $\left(K_{\mathrm{rs}}\right)$, the root distribution, and the difference between the local soil water potential and the water potential at the root collar. Variations of this potential difference with depth in the root zone lead to water uptake compensation. For crops with small lateral variations in root length density (RLD), this 3-D model could be upscaled to a 1-D model (Couvreur et al., 2014a) which shows similarities to the models of Nimah and Hanks (1973) and of Amenu and Kumar (2008). Cai et al. (2017) obtained the root hydraulic parameters of the 1-D upscaled Couvreur model for winter wheat (Couvreur et al., 2014a) by inverse modeling using time series of soil water potential, water content, and root length density measurements in the field. Since the upscaled root hydraulic parameters have physical meaning, the upscaled parameters obtained from inverse modeling could be compared to and were found to be consistent with parameters that were derived from direct measurements of hydraulic properties of root segments and models of the hydraulic root architecture (Couvreur et al., 2014a).

Another way to validate the inversely estimated parameters is to evaluate whether the model is able to predict the RWU and its reduction when SWP decreases. For crops with a small water capacity, the RWU corresponds closely with the transpiration rate. Measurements of crop transpiration can therefore be used to parameterize or validate RWU models.

Many techniques have been used to investigate transpiration ranging between the single plant and catchment scale (Twine et al., 2000; Allen et al., 1989; Jaeger and Kessler, 1997). At the field plot scale, weighing lysimeters allow transpiration to be measured (e.g., Groh et al., 2016; Garré et al., 2011). A disadvantage of lysimeters is that they are costly and, although possible (e.g., Garré et al., 2011; Vandoorne et al., 2012), root distributions are difficult to measure in lysimeters and their spatial growth is influenced by the confined soil space, which also frequently causes undesired boundary effects (e.g., high root length densities at lysimeter walls). Measuring sap flow with the thermoelectric method is a direct and in situ technique which was discovered by Huber (1932). It was used to estimate transpiration for different trees species (Granier et al., 1996; Cermak et al., 2004; Massai and Remorini, 2000) and crops (Chabot et al., 2005; Langensiepen et al., 2014; Cohen et al., 1993). Due to limitations of sensor installation on small and vulnerable crop stems, sap flow measurements on crops with small stem diameters of less than $5 \mathrm{~mm}$ are practically challenging. Senock et al. (1996) provided first sap flow measurements for wheat under field conditions but the values were within $10 \%$ of gravimetric measurements and the experimental verification of a high sap flow rate (up to $5 \mathrm{gh}^{-1}$ ) is not available. 
Applying an empirical method for calculating sap flow from standard stem heat sensor outputs, Langensiepen et al. (2014) obtained close agreements between measured sap flow and transpiration rates measured with a standard eddy covariance system. Continuous sap flow measurements can be carried out with modern logging techniques (e.g., multiplexer and data logger), providing insight into the temporal dynamics of transpiration and how for instance RWU changes when SWP decreases over time. The use of sap flow measurements to validate theories of RWU was demonstrated for trees (Gong et al., 2006; Howard et al., 1996; Green and Clothier, 1998), but for crops, in particular wheat, such a validation has not yet been performed under field conditions.

The main objective of this study is to investigate whether physically based (1-D Couvreur model) and empirical (Feddes-Jarvis model) models for RWU can simulate the effect of different soil water availability levels on wheat RWU resulting from differences in soil water application and differences in soil water retention characteristics. This includes testing whether parameters of these models can be calibrated using measurements of soil water content, water potential, and root density and validating the calibrated model against sap flow measurements. Second, we investigated whether differences in crop shoot and root developments between treatments with differences in soil water availability lead to different model parameter estimates and whether these parameters estimates can be linked to directly observable properties of the root system.

Therefore, water potentials and contents, root distributions, crop development, and sap flow were monitored in six plots (two soil types and three water application treatments) and used to parameterize two RWU models: the FeddesJarvis model (FJ model) and the physically based Couvreur model (C model).

\section{Materials and methods}

The experimental setup of the plots was described in detail in Cai et al. (2016) and the model setup and the inverse modeling procedure that was used to determine the parameters by Cai et al. (2017). For more detailed information about the setup and the inverse modeling procedure, we refer the reader to these publications.

\subsection{Setup of the test site}

Two instrumented rhizotron facilities were constructed on the upslope and the downslope of a cropped field in Selhausen (Germany, $50^{\circ} 52^{\prime} \mathrm{N}, 6^{\circ} 27^{\prime} \mathrm{E}$ ). The field is on a westfacing slope (smaller than $4^{\circ}$ ) and characterized by a high stone content (up to $60 \%$ ) in the upslope and silty texture in the downslope. The soil water content at field capacity $(-330 \mathrm{~cm})$ was 0.15 and 0.09 in the topsoil $(0-30 \mathrm{~cm})$ and subsoil $(30-120 \mathrm{~cm})$ of the stony soil and 0.37 and 0.29 in

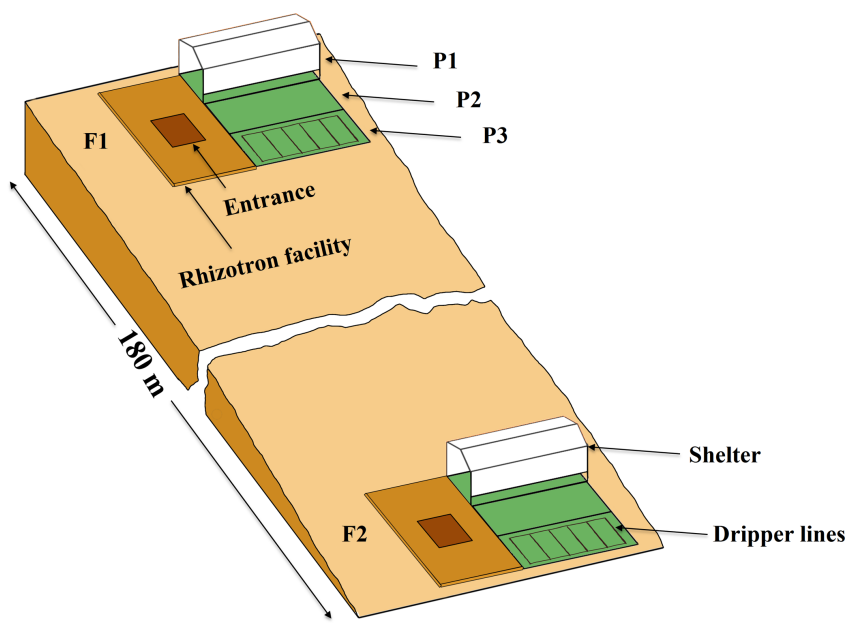

Figure 1. Sketch map of the location and the setup of the upper (F1, stony soil) and lower (F2, silty soil) rhizotron facilities. P1, P2, and P3: the sheltered, rainfed, and irrigated plots.

the top- and subsoil of the silty soil, respectively. The water content at wilting point $(-15000 \mathrm{~cm})$ was 0.07 and 0.06 in the top- and subsoil of the stony soil and 0.25 and 0.19 in the top- and subsoil of the silty soil, respectively. Each facility was divided into three plots of $7 \mathrm{~m}$ length $\times 3.25 \mathrm{~m}$ width. To produce a gradient in soil water availability, one plot was sheltered from rain, one plot was rainfed, and one plot was irrigated by drip irrigation. A sketch of the facilities with the location of the sheltered, rainfed, and irrigated plots and the wooden framed trenches is shown in Fig. 1.

Precipitation and other meteorological data for the calculation of reference evapotranspiration $\left(\mathrm{ET}_{o}\right)$ using the FAO56 Penman-Monteith equation (Allen et al., 1998) were obtained from a weather station located between the two facilities ( $21 \mathrm{~m}$ away from the lower facility). The average annual precipitation for the past 50 years in this area was $699 \mathrm{~mm}$ (Knaps, 2016).

Winter wheat (variety Ambello) was sown at a density of 300-320 seeds m ${ }^{-2}$ on 31 October 2013 in all plots and harvested on 17 July 2014 in the stony soil (upper facility) and on 31 July 2014 in the silty soil (lower facility) as the contrasting soil water regimes in the two soils affected ripening times. Total shoot biomass was harvested in an area of $7.31 \mathrm{~m}^{2}(3.25 \mathrm{~m} \times 2.25 \mathrm{~m})$ in each plot and weighed after oven drying. Leaf area index (LAI) was measured using a plant canopy analyzer (LAI-2200, LI-COR, Inc. USA) and ranged from 0.8 to 2.5 in the stony soil and from 0.8 to 4.0 in the silty soil between 8 April and 14 July 2014 (Fig. 2a). Precipitation depth between the seeding and harvest was $434.49 \mathrm{~mm}$ in the rainfed plot of the stony soil and $495.89 \mathrm{~mm}$ of the silty soil, the difference resulting from different growth period lengths in both facilities. Figure $2 b$ shows the cumulative amount of water received by the three plots in both soils. The aridity index, defined as the ratio of 
(a)
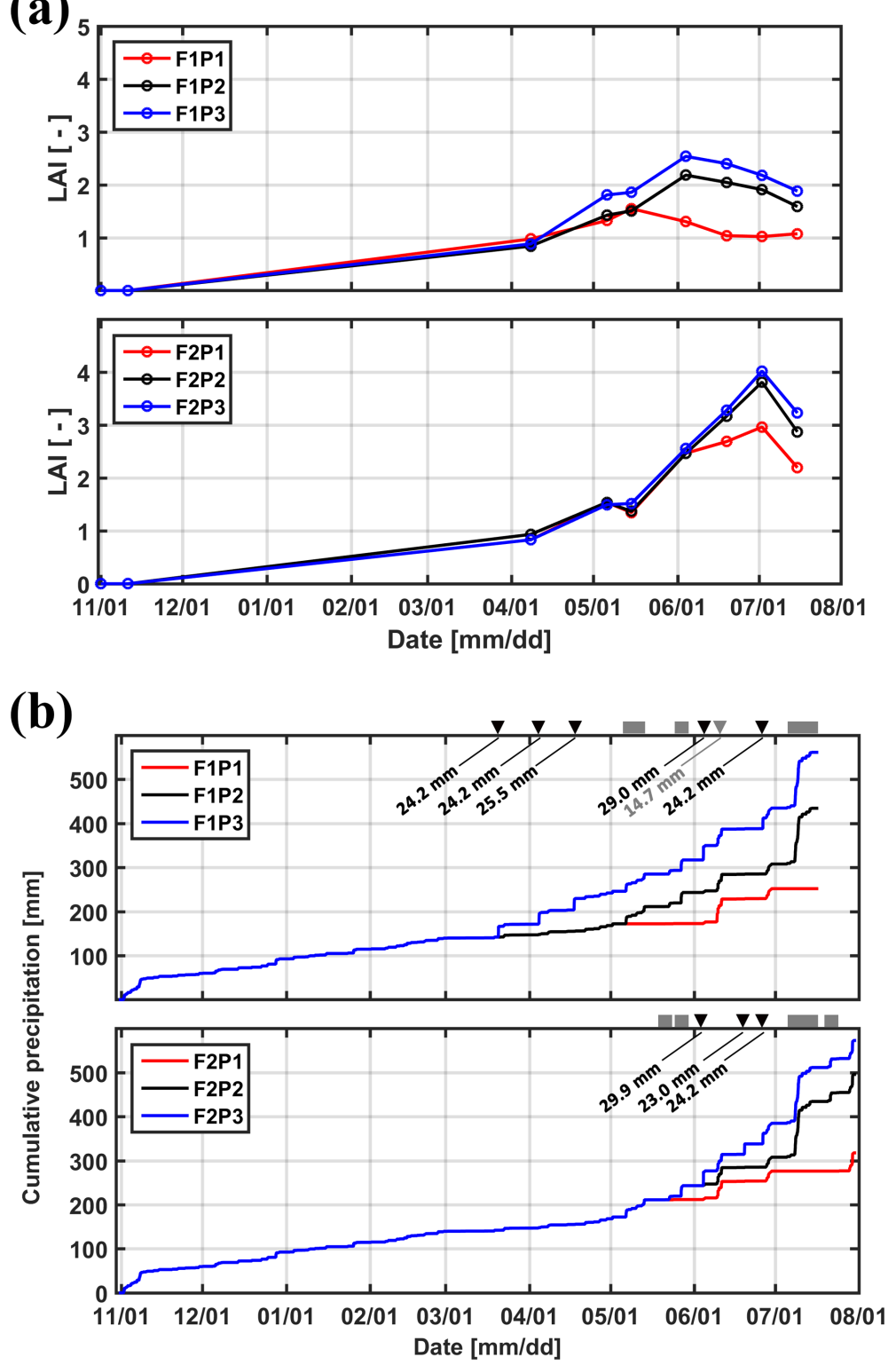

Figure 2. (a) Measured leaf area index (LAI) in the three plots (P1: sheltered; P2: rainfed; P3: irrigated) of the two facilities (F1: stony soil, F2: silty soil). (b) Cumulative precipitation and irrigation applied to the sheltered (P1), rainfed (P2), and irrigated (P3) plots of the stony (F1) and silty (F2) soils. Gray squares: sheltered period; black downward-facing triangle: irrigation in P3; gray downward-facing triangle: irrigation in $\mathrm{P} 1$.

precipitation to reference evapotranspiration, was 0.7 from 11 February (date for first root measurement) to 16 July (one day before crop harvest in the stony soil) in the test site. In the sheltered plots, the aridity index was 0.33 and 0.37 for the stony and silty soils, respectively, from 11 February to 16 July.

\subsection{Measurements of soil moisture, root distribution, and sap flow}

\subsubsection{Soil water content and potential}

Time domain reflectometer (TDR) sensors, tensiometers (T4e, UMS GmbH, München, Germany), and matrix water potential sensors (MPS-2, Decagon Devices Inc., UMS $\mathrm{GmbH}$ München, Germany) were installed in each plot at $0.1,0.2,0.4,0.6,0.8$, and $1.2 \mathrm{~m}$ depth in the vertical walls of the facilities to monitor hourly SWC and soil water potential. 


\subsubsection{Root observation}

Root distributions were measured nondestructively at weekly intervals from 11 February to 11 July 2014 in the stony soil and from 14 March to 24 July 2014 in the silty soil with a minirhizotron camera (Bartz Technology Corporation, Carpinteria, CA, USA) in $7 \mathrm{~m}$ long horizontally installed rhizotubes. Three replicates of rhizotubes were installed at the same depths as the soil moisture sensors. Root images with the size of $16.5 \mathrm{~mm} \times 23.5 \mathrm{~mm}$ were taken from left and right sides at 20 fixed locations along each tube and were analyzed subsequently using the software Rootfly (Wells and Birchfield, 2009) to determine the length of roots per area of the image. Root length densities were therefore expressed in units of length per surface. To calculate the total root length below a unit surface area, both root length and root counts per image surface were considered in Cai et al. (2017). We assumed that root lengths in the images were proportional to root counts. Using root counts has the advantage of avoiding the use of the empirical soil thickness (e.g., $2 \mathrm{~mm}$ ) viewed by the camera in the estimation of absolute total root length. The root counts were associated with a soil volume that corresponds with the diameter (height, $64 \mathrm{~mm}$ ), the radius (width, $32 \mathrm{~mm}$ ) of the tube, and the image width (depth, $16.5 \mathrm{~mm}$ ) to obtain an estimate of root length density (Cai et al., 2017). The root densities were subsequently integrated over depth to obtain the total root length below a unit surface area.

\subsubsection{Sap flow}

Sap flow was determined with SGA3 Dynagage sap flow sensors (Dynamax Inc., Houston, USA) in five randomly selected wheat tillers located in the center of each plot. They were continuously operated from 23 May to 6 July 2014. Signals of the sap flow sensors were scanned every $60 \mathrm{~s}$ with Dynamax control units consisting of voltage regulators, AM 16/32B multiplexers, and CR1000 data loggers (Dynamax Inc., Houston, USA; Campbell Scientific, Logan, Utah). The readings were averaged every $10 \mathrm{~min}$, stored in a text file and processed with an R script containing the standard calculation procedures for computing sap flow from Dynagage files (Dynamax, 2009) and an improved post-processing method for removing the noise from standard calculations (Langensiepen et al., 2014). Tiller density was determined in a fixed area of $1 \mathrm{~m}^{2}$ for each plot and used for converting average sap flow rate $\left(\mathrm{gd}^{-1}\right.$ tiller $\left.^{-1}\right)$ to an area-based transpiration rate $\left(\mathrm{cm} \mathrm{d}^{-1}\right)$.

\subsection{Root water uptake models and parameterizations}

\subsubsection{Model description}

We used two 1-D RWU models: the FJ model (Šimůnek and Hopmans, 2009) and the physically based C model (Couvreur et al., 2012, 2014a), both of which considered water uptake compensation. The two models have been implemented in Hydrus-1-D (Šimůnek et al., 2016). The sink term in the two models is calculated with the following equations:

$$
\begin{aligned}
S_{\mathrm{FJ}}(z)= & T_{\mathrm{pot}} \alpha_{\mathrm{F}}(h) \operatorname{NRLD}(z) \gamma \\
S_{\mathrm{C}}(z)= & \min \left(T_{\mathrm{pot}}, T_{\mathrm{act}}\right) \operatorname{SSF}(z) \\
& +K_{\mathrm{comp}}\left(H(z)-H_{\mathrm{e}}\right) \operatorname{SSF}(z),
\end{aligned}
$$

where $S_{\mathrm{FJ}}$ and $S_{\mathrm{C}}$ are the sink terms accounting for RWU rates in, respectively, the $F J$ and $C$ models $\left(\mathrm{L}^{3} \mathrm{~L}^{-3} \mathrm{~T}^{-1}\right), z$ the elevation (L), $T_{\text {pot }}$ and $T_{\text {act }}$ the potential transpiration and transpiration under water stress condition $\left(\mathrm{L} \mathrm{T}^{-1}\right), \alpha_{\mathrm{F}}$ the water stress function described below $(-), h$ the measured soil water pressure head (SWP) (L), NRLD the normalized root length density $\left(\mathrm{L}^{-1}\right), \gamma$ the water uptake compensatory factor $(-), \operatorname{SSF}(z)$ the standard sink term fraction $\left(\mathrm{L}^{-1}\right)$, which corresponds with the uptake at a certain depth when the hydraulic heads in the root zone are uniform, $K_{\text {comp }}$ the compensatory RWU conductance of the root system $\left(\mathrm{T}^{-1}\right), H$ the total hydraulic head (sum of pressure head and elevation head) (L), and $H_{\mathrm{e}}$ the effective root zone hydraulic head (L). $H_{\mathrm{e}}$ is the integration of the soil hydraulic head and root distribution along the rooting depth $\left(l_{z},\left(\mathrm{~L}^{-1}\right)\right)$ profile:

$H_{\mathrm{e}}=\int_{0}^{l_{z}} H(z) \operatorname{SSF}(z) \mathrm{d} z$.

When the total resistance to flow in the axial direction is small (large axial conductance and/or small transport distance), then the 3-D version of the $\mathrm{C}$ model reproduces the flow in the root system exactly that is predicted by solving the flow equations in the root system for boundary conditions that correspond with the soil water potentials (Couvreur et al., 2014b, 2012). In these conditions, $K_{\text {comp }}$ should be equal to $K_{\mathrm{rs}}$. When this condition does not hold, then the model is not an exact solution anymore but the impact of the resistance to flow in the axial direction can be represented by using a smaller $K_{\text {comp }}$ (Couvreur et al., 2014b). This was shown by comparing detailed simulations using a coupled soil-root model (Javaux et al., 2008) against simulations with the $\mathrm{C}$ model (Couvreur et al., 2014b). The second assumption is related to the upscaling. The model we are using is a 1-D version of the 3-D model. It assumes that the water potentials at the root interface can be represented by the average bulk water potentials at a certain depth. Based on numerical simulations, it was found that this assumption seems to hold well for crops with a more or less homogeneous lateral distribution of the roots (like wheat) but less so for crops for which there is quite a lot of lateral variability in root density (like maize) (Couvreur et al., 2014a). The third assumption that we made (which is not a model assumption but an assumption about the link between the standard uptake fraction and the root density) is that the standard uptake fraction, SSF, is equal to the NRLD. This assumption can be made when the average radial conductances of root segments at a certain 
Table 1. Crop coefficients $\left(K_{\mathrm{c}}\right)$ of winter wheat in the stony $(\mathrm{F} 1)$ and silty $(\mathrm{F} 2)$ soils in different growing periods. $K_{\mathrm{c}}$ was calculated according to Allen et al. (1998).

\begin{tabular}{cccc}
\hline & $\begin{array}{c}\text { Initial period } \\
\text { 31 Oct 2013-27 Feb 2014 }\end{array}$ & $\begin{array}{c}\text { Mid-season } \\
\text { 8 May-27 Jun 2014 (F1) } \\
\text { 8 May-09 Jul 2014 (F2) }\end{array}$ & $\begin{array}{c}\text { Late stage } \\
\text { 37 Jul 2014 (F1) }\end{array}$ \\
& & 1.26 & 0.27 \\
F1 & 0.93 & 1.26 & 0.29 \\
F2 & 0.93 & Jul 2014 (F2) \\
\hline
\end{tabular}

depth do not vary a lot with depth and when the resistance to flow in the axial direction is not too large.

$T_{\text {pot }}$ is given by

$T_{\text {pot }}=E T_{o} K_{\mathrm{c}}\left(1-e^{-k \cdot \mathrm{LAI}}\right)$,

where $K_{\mathrm{c}}$ is the crop coefficient (-) that accounts for changes in evapotranspiration with crop development (Allen et al., 1998) (Table 1), LAI the leaf area index (-), and $k$ the light extinction coefficient (0.6 was used; Xin-Yang and YangRen, 2013; Rodriguez et al., 2001; Oroud, 2012; Bingham et al., 2009). In the $\mathrm{C}$ model, the leaf water hydraulic head, $H_{\text {leaf }}(\mathrm{L})$, is related to $T_{\text {pot }}$, the equivalent root system hydraulic conductance, $K_{\mathrm{rs}}\left(\mathrm{T}^{-1}\right)$, and the effective root zone hydraulic head, $H_{\mathrm{e}}(\mathrm{L})$, by

$T_{\text {pot }}=K_{\mathrm{rs}}\left(H_{\mathrm{e}}-H_{\text {leaf }}\right)$,

as long as $H_{\text {leaf }}(\mathrm{L})$ is larger than a critical leaf hydraulic head, $H_{\text {leaf_crit }}(-16000 \mathrm{~cm}$ was used in this study, Wesseling, 1991). When the leaf water potential equals $H_{\text {leaf_crit }}$, the transpiration rate is reduced and the actual transpiration rate $T_{\text {act }}$ is obtained from

$T_{\text {act }}=K_{\mathrm{rs}}\left(H_{\mathrm{e}}-H_{\text {leaf_crit }}\right)$.

The parameters $K_{\mathrm{rs}}$ and $K_{\mathrm{comp}}\left(\mathrm{T}^{-1}\right)$ of the $\mathrm{C}$ model depend on the root development since the root system conductance increases when the root system grows. In line with Cai et al. (2017), we assumed that $K_{\text {rs }}$ and $K_{\text {comp }}$ were proportional to the total root length of the root system that is derived from the integral of the RLD over depth.

For the FJ model, the RWU under water stress conditions was constrained by a piecewise function $\left(\alpha_{\mathrm{F}}\right)$ that is dependent on SWP:

$\alpha_{\mathrm{F}}(h)=\left\{\begin{array}{ll}0 & h \notin[h 4, h 1) \\ \frac{h-h_{1}}{h_{2}-h_{1}} & h \in(h 2, h 1] \\ 1 & h \in[h 3, h 2] \\ \frac{h-h_{4}}{h_{3}-h_{4}} & h \in[h 4, h 3)\end{array}\right.$,

where $h_{1,4}$ and $h_{2,3}$ are the thresholds of SWP where RWU is completely constrained $(S=0)$ and has reached a maximum, respectively. The value of $h_{3}$ is a function of $T_{\text {pot }}$ (Brandyk and Wesseling, 1985):

$h_{3}= \begin{cases}h_{31} & T_{\text {pot }} \in\left[0, T_{31}\right] \\ h_{3 \mathrm{~h}}+\frac{\left(h_{31}-h_{3 \mathrm{~h}}\right)\left(T_{3 \mathrm{~h}}-T_{\mathrm{pot}}\right)}{\left(T_{3 \mathrm{~h}}-T_{31}\right)} & T_{\text {pot }} \in\left(T_{31}, T_{3 \mathrm{~h}}\right), \\ h_{3 \mathrm{~h}} & \text { else }\end{cases}$
Table 2. Parameters of soil hydraulic properties in the topsoil ( 0 $30 \mathrm{~cm})$ and subsoil $(30-120 \mathrm{~cm})$ of the stony (F1) and silty (F2) soils. $\theta_{\mathrm{r}}$ and $\theta_{\mathrm{s}}$ are residual and saturated soil water content, respectively. $\alpha$ and $n$ are curve-fitting parameters.

\begin{tabular}{lrrrr}
\hline & $\begin{array}{r}\theta_{\mathrm{r}} \\
\mathrm{cm}^{3} \mathrm{~cm}^{-3}\end{array}$ & $\begin{array}{r}\theta_{\mathrm{s}} \\
\mathrm{cm}^{3} \mathrm{~cm}^{-3}\end{array}$ & $\begin{array}{r}\alpha \\
\mathrm{cm}^{-1}\end{array}$ & $n$ \\
\hline F1 topsoil & 0.0430 & 0.3256 & 0.0361 & 1.3860 \\
F1 subsoil & 0.0543 & 0.2286 & 0.0495 & 1.5340 \\
F2 topsoil & 0.1392 & 0.4089 & 0.0231 & 1.2920 \\
F2 subsoil & 0.1304 & 0.4119 & 0.0050 & 1.1920 \\
\hline
\end{tabular}

where $T_{3 \mathrm{~h}}$ and $T_{31}$ were set to 0.02 and $0.004 \mathrm{cmh}^{-1}$ (Yang et al., 2009).

The water uptake compensation in the $\mathrm{C}$ model is described by the second term on the right-hand side of Eq. (3). For the FJ model it is controlled by an empirical factor $(\gamma)$ that is water-stress-related:

$\gamma=1 / \max \left(\omega, \omega_{\mathrm{c}}\right)$
$\omega=\int_{l_{z}} \alpha_{\mathrm{F}}(h) \operatorname{NRLD}(z) \mathrm{d} z$

where $\omega_{\mathrm{c}}$ is the critical water stress threshold (-) which ranges between 0 and 1, corresponding to, respectively, full compensation and no compensation (Šimůnek and Hopmans, 2009; Jarvis, 1989).

The soil hydraulic properties were described by the combined Mualem-van Genuchten equations (Mualem, 1976; Van Genuchten, 1980):

$$
\begin{aligned}
& \theta(h)= \begin{cases}\theta_{\mathrm{r}}+\frac{\theta_{\mathrm{s}}-\theta_{\mathrm{r}}}{\left[1+|\alpha h|^{n}\right]^{m}} & h \in(-\infty, 0) \\
\theta_{\mathrm{s}} & \text { else }\end{cases} \\
& K\left(S_{\mathrm{e}}\right)=K_{\mathrm{s}} S_{\mathrm{e}}^{l}\left[1-\left(1-S_{\mathrm{e}}^{1 / m}\right)^{m}\right]^{2},
\end{aligned}
$$

where $\theta_{\mathrm{r}}$ and $\theta_{\mathrm{S}}$ are the residual and saturated water content $\left(\mathrm{L}^{3} \mathrm{~L}^{-3}\right) ; \alpha\left(\mathrm{L}^{-1}\right), n(n>1), m(m=1-1 / n)$, and $l$ are shape parameters; $K$ and $K_{\mathrm{s}}$ are the unsaturated and saturated hydraulic conductivity $\left(\mathrm{L} \mathrm{T}^{-1}\right) ; S_{\mathrm{e}}$ is the effective saturation $(-):\left(\theta-\theta_{\mathrm{r}}\right) /\left(\theta_{\mathrm{s}}-\theta_{\mathrm{r}}\right)$. 


\subsubsection{Inverse modeling and model setup}

The parameters of the van Genuchten (1980) soil water retention function were fitted using measured SWC and soil water head data (Cai et al., 2016) (Table 2). The parameters $K_{\mathrm{s}}, l, h_{3 \mathrm{~h}}, h_{31}$, and $\omega_{\mathrm{c}}$ of the FJ model and $K_{\mathrm{rs}}$ and $K_{\text {comp }}$ of the $\mathrm{C}$ model were inversely estimated by fitting the simulated SWP and SWC to the measured SWP and SWC. For the stony soil, a time series from 11 February to 14 July 2014 was used, and for the silty soil, a time series from 22 May to 30 July 2014 was used. Besides the time series of the SWP and SWC, also other variables that were derived from these time series, such as changes in SWP and SWC over time and water storage in the soil profile, were also included in the objective function that was minimized in the fitting procedure as described in Cai et al. (2017) and we refer the reader to that paper for further details. Briefly, the objective function in this study was the weighted sum of normalized root mean squared errors of different variables: SWC, SWP, and changes in SWC and SWP over time, total SWC in the soil profile, and corresponding changes over time. In the current study, observations and simulations of soil moisture dynamics for the three treatments per soil type (i.e., stony and silty soils) were lumped into one objective function, whereas Cai et al. (2017) only used data from the sheltered plot in the stony soil. Hence, for each soil type, the same soil and RWU parameters were used to simulate RWU for the three treatments. But, since the two objective functions with data from the two different soil types were optimized independently, different soil and RWU parameters were obtained for the two different soils.

The 1-D Richards equation was solved numerically using Hydrus in a $145 \mathrm{~cm}$ deep soil profile for the stony soil and in a $300 \mathrm{~cm}$ deep profile for the silty soil using a spatial discretization of $1 \mathrm{~cm}$. Two soil layers with different hydraulic properties, the topsoil $(0-30 \mathrm{~cm})$ and the subsoil $(30-145 \mathrm{~cm}$ for the stony soil and $30-300 \mathrm{~cm}$ for the silty soil), were considered at both facilities. An atmospheric boundary condition was used at the top and a free drainage boundary condition at the bottom (Šimůnek et al., 2013). The soil water pressure heads measured at the start of the simulation period were used as initial conditions. In order to consider the root development during the growing period, the simulation period was split up into 1-week periods during which a constant RLD profile was assumed. The parameters $K_{\text {rs }}$ and $K_{\text {comp }}$ of the $\mathrm{C}$ model, which were assumed to depend on the total root length, were hence adjusted at weekly intervals. One set of parameters, $K_{\text {rs_ini }}$ and $K_{\text {comp_ini }}$, which correspond with the RWU parameters from the sheltered plot during the first week of the simulation period, were estimated using inverse modeling. $K_{\mathrm{rs}}$ and $K_{\text {comp }}$ during the $i$ th week of a certain water treatment were obtained by scaling $K_{\text {rs_ini }}$ and $K_{\text {comp_ini }}$ with the ratio of the integrated root length (integration of RLD over the soil profile) in week $i$ in that water treatment to the integrated root length during the first week in the shel- tered plot. The initial conditions of a 1-week period were derived from the simulated SWP profile at the end of the previous 1-week simulation period.

The model results were evaluated in terms of root mean square error (RMSE), mean bias error (ME), and an index of agreement $(d)$ :

$$
\begin{aligned}
& \mathrm{RMSE}=\sqrt{\left[\sum_{i=1}^{N}\left(\mathrm{Sim}_{i}-\mathrm{Obs}_{i}\right)^{2}\right]} / N \\
& \mathrm{ME}=\left[\sum_{i=1}^{N}\left(\mathrm{Sim}_{i}-\mathrm{Obs}_{i}\right)\right] / N \\
& d=1-\left[\sum_{i=1}^{N}\left(\mathrm{Sim}_{i}-\mathrm{Obs}_{i}\right)^{2}\right] / \\
& \\
& {\left[\sum_{i=1}^{N}\left(\left|\operatorname{Sim}_{i}-\overline{\mathrm{Obs}}\right|+\left|\mathrm{Obs}_{i}-\overline{\mathrm{Obs}}\right|\right)^{2}\right],}
\end{aligned}
$$

where Sim and Obs are simulated and measured variables, $i$ is the index of a given variable, and $N$ is the number of observations.

\section{Results and discussion}

We first discuss the effect of water treatments and soil textures on crop and root development. In the second part, we discuss the inverse estimation of RWU parameters of the FJ and $\mathrm{C}$ models from measured SWC and SWP. In the third part, simulated RWU by the two models in the different soils and water treatments is discussed and compared with sap flow measurements. In the last part, we discuss a sensitivity analysis that was carried out to evaluate the effect of the differing development of the wheat crop in the different soils and water treatments on the simulated water uptake.

\subsection{Effect of water treatment on crop and root development}

Tiller densities and crop biomass in the three different water treatments in the two soils are shown in Table 3. Contrasting soil water availability affected crop biomass growth and yield. Less water application (the sheltered plot received 55.13 and $44.52 \%$ of the water received by the irrigated plots in the stony and silty soil, respectively; Fig. $2 b$ ) reduced the tiller density in the sheltered plot with respect to the irrigated plot by $38.4 \%$ in the stony plots and $11.3 \%$ in the silty plots, and reduced the biomass by $58.8 \%$ in the stony plots and $40.8 \%$ in the silty plots. The biomass of wheat in the treatments that received less water was reduced more strongly than the tiller density as was also reported by Musick and Dusek (1980). The tiller density and biomass were generally higher in the silty soil than in stony soil, especially for the sheltered plots. Similar differences were found in LAI between the two soils (Fig. 2a). The peak LAI was higher in each plot of the silty soil than the corresponding plot of the stony soil. The higher water-holding capacity of the silty soil supplying more available water in the subsoil for root extrac- 
Table 3. Tiller density (measured on 11 Jun 2014), crop biomass (including straw and grain, which were measured after the harvest), ratio of leaf area index (LAI) to tiller density, and maximal root length in the three plots (P1: sheltered; P2: rainfed; P3: irrigated) of the stony (F1) and silty (F2) soils.

\begin{tabular}{lrrrr}
\hline & & P1 & P2 & P3 \\
\hline Tiller density $\left(\mathrm{m}^{-2}\right)$ & F1 & 228 & 310 & 370 \\
& F2 & 346 & 380 & 390 \\
Biomass $\left(\mathrm{kg} \mathrm{m}^{-2}\right)$ & F1 & 0.2951 & 0.6719 & 0.7164 \\
& F2 & 0.7164 & 1.0659 & 1.2097 \\
LAI/tiller density $\left(\mathrm{m}^{2}\right)$ & F1 & 0.0050 & 0.0067 & 0.0067 \\
& F2 & 0.0075 & 0.0074 & 0.0075 \\
Maximal total root length $\left(\mathrm{m} \mathrm{m}^{-2}\right)$ & F1 & 2533.9 & 2941.9 & 3431.2 \\
& F2 & 6787.4 & 7043.9 & 7024.1 \\
\hline
\end{tabular}

tion may account for the difference. Note that there was no difference of LAI among all the plots of the two soils until the beginning of April. The deviation of LAI between the plots with different water treatments started around 50 days earlier in the stony than in the silty soil even though the irrigation was applied earlier in the stony plot. This indicated that more water was available in the silty soil than in the stony soil due to the different soil properties.

As for the belowground part of the crops, RLD decreased gradually downwards for all plots of the two facilities at the beginning of the measurements (Fig. 3). The RLD in the shallow layers $(-10$ to $-20 \mathrm{~cm})$ was similar in the stony and silty soils, ranging from 0.12 to $0.67 \mathrm{~cm} \mathrm{~cm}^{-2}$. However, larger differences in RLD between the two soils were observed at greater depths ( -60 to $-120 \mathrm{~cm}$ depth). In the stony soil, maximal root densities were observed at shallower depths $(-40 \mathrm{~cm}$ in the sheltered and irrigated plots and $-60 \mathrm{~cm}$ in the rainfed plot) than in the silty soil $(-60 \mathrm{~cm}$ in the irrigated and $-80 \mathrm{~cm}$ in the sheltered and rainfed plots). Furthermore, the maximal root length densities were considerably higher in the silty soil than in the stony soil (note the difference in color scale). The root density distributions showing maximal densities at greater depths are markedly different from the root density profiles that have been observed for winter wheat using soil coring in loamy soil (Zhang et al., 2004) and in soils with seven different textures (from clay to sandy loam) (e.g., White et al., 2015; Zhang et al., 2004). This might on the one hand be due to a great amount of water stored at those depths in the silty soil but probably also due to nutrient distribution in the soil profile at this site, which might have promoted root development in deeper soil layers (Thorup-Kristensen et al., 2009; Yang et al., 2003). On the other hand, some studies indicated that root length densities estimated from rhizotubes may underestimate the root densities in surface soil layers due to temperature effects (Fitter et al., 1998) or roots growing parallel to the horizontal plane not intersecting the tube surface (Meyer and Barrs, 1991). We obtained root lengths ranging from 1.5 to $7.0 \mathrm{~km} \mathrm{~m}^{-2}$, which is within the range of the results from White et al. (2015) who investigated root development of 11 winter wheat varieties in 4 different soils (from clay to sandy loam) in the UK. They found an average of $9.8 \mathrm{~km} \mathrm{~m}^{-2}$ from the samples to $1 \mathrm{~m}$ depth. The lower estimate might be due to an underestimation of the root density in the upper $30 \mathrm{~cm}$ using the rhizotubes.

Root senescence was observed at the end of the growing season. It started in the upper soil layers and progressively moved to deeper layers, which is more obvious in the three plots of the stony soil after 21 May. Furthermore, root senescence in shallower layers (above $30 \mathrm{~cm}$ ) occurred simultaneously with root development in deeper layers (below $30 \mathrm{~cm}$ ).

The observed root development in the two different soils and for the different water treatments show opposite reactions to soil water availability. On the one hand, lower water availability in the stony soil led to a lower root density and lower total root length than in the silty soil (Table 3). The same behavior was observed when comparing the sheltered with the rainfed and irrigated plots in the stony soil. In the silty soil, however, an increase in root density was observed when water availability decreased. When plants experience water deficits, the aboveground shoot development is reduced by different mechanisms (e.g., reduced leaf expansion by lower turgor, enhanced respiration, stomatal closure, and reduced photosynthesis) (Bunce, 1978; Wesselius and Brouwer, 1972; Mansfield and Atkinson, 1990). The reduction in shoot growth can be counteracted with an increase in carbon allocation to the root zone as was shown in a review by Poorter et al. (2012) on environmental effects on biomass allocation. The ratio of total root length to aboveground biomass (Fig. 4) suggests that indeed a larger fraction of carbon was allocated to the roots in the sheltered plots than in the rainfed or irrigated plots both in the stony and silty soils. Although the differences in the ratio between the two soils are not so large, the total root length per kilogram of shoot biomass was larger in the silty soil than in the stony soil. At first sight, this seems contradictory to the lower water (and nutrient) availability in the stony soil than in the silty soil. This might reflect the fact that other factors like soil 

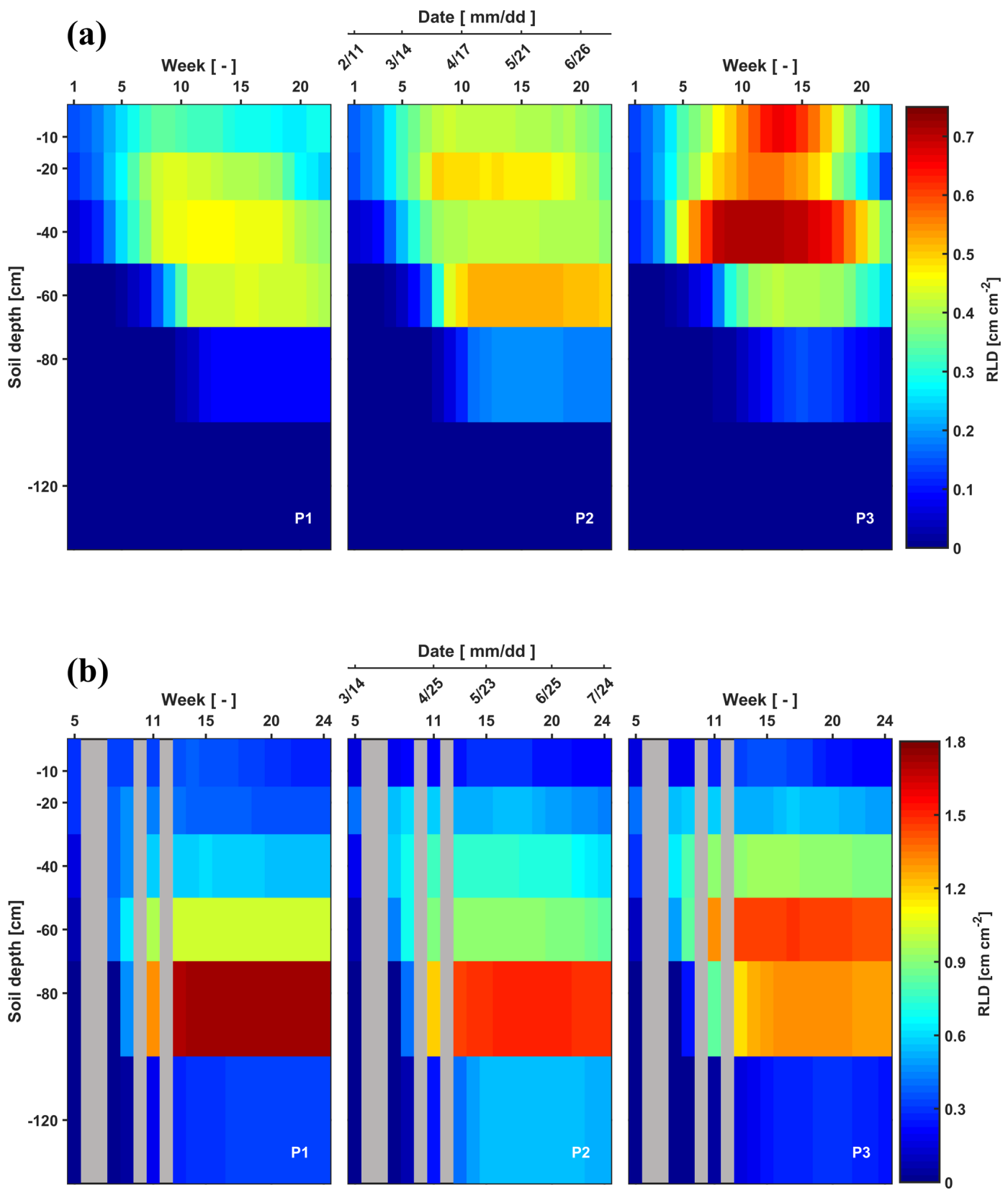

Figure 3. Depth-time distribution of root length density (RLD) in the three plots (P1: sheltered; P2: rainfed; P3: irrigated) of (a) the stony (F1) soils and (b) silty (F2) soils from 11 February to 11 July 2014 and from 14 March to 24 July 2014, respectively. There are no measurements in the gray grids.

mechanical strength may have restricted root growth more in the stony soil than in the silty soil (Unger and Kaspar, 1994; Merotto Jr and Mundstock, 1999).

\subsection{Inverse estimation of soil and root water uptake parameters of the Feddes-Jarvis and Couvreur models from soil water contents and water potential measurements}

Time series of observed and simulated SWC and SWP are illustrated in Figs. 5 and 6 for the plots with different water treatments of the stony and silty soils, respectively. As expected, the irrigated plots were wetter than the rainfed and sheltered plots but in the top layers of the silty soil measured 


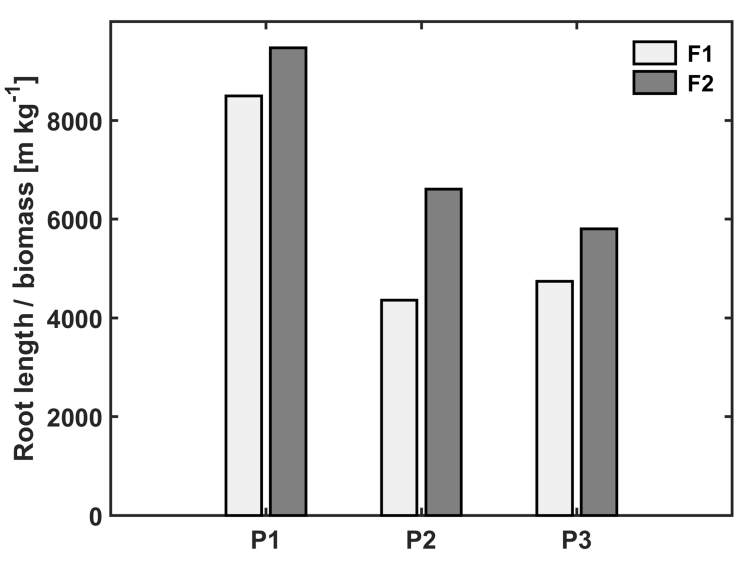

Figure 4. Ratio of total root length to biomass in the three plots (P1: sheltered; P2: rainfed; P3: irrigated) of the stony (F1) and silty (F2) soils.

water contents and pressure heads decreased between irrigation events to similarly low values as in the nonirrigated plots. For the period in which measurements were carried out in both soils (from the middle of May until the beginning of July) the SWPs in the sheltered and rainfed plots were more negative in the stony than in the silty soil, suggesting that the crop experienced more water stress in the stony soil. In both soils, the top layer dried out considerably and low SWP $\left(-10^{4} \mathrm{~cm}\right)$ was reached as a result of high evaporation and transpiration demand. In the sheltered and rainfed plots of the stony soil, such low SWPs were also reached in the deeper soil layers $(-60$ and $-80 \mathrm{~cm})$, whereas SWPs stayed higher at those depths in the silty soil due to the larger waterholding capacity of the silty soil.

The statistics RMSE, ME, and $d$ of the SWC and SWP simulated by the two models are listed in Table S1 in the Supplement. Since the statistics were very similar for both models, there was no notable difference between simulation accuracies of the FJ and C models. The values of RMSE for SWC in the stony soil $\left(0.02\right.$ to $\left.0.03 \mathrm{~cm}^{3} \mathrm{~cm}^{-3}\right)$ were almost half of those in the silty soil, whereas for SWP the values did not differ much between the two soils (from 0.3 to $0.9 \log _{10}$ $(\mathrm{cm})$ ). The larger RMSE of SWC in the silty soil is also due to the larger uncertainty in the measured SWC due to the variability of SWC between the four replicate TDR sensors (standard error of the sample mean reached $0.035 \mathrm{~cm}^{3} \mathrm{~cm}^{-3}$ ) (Cai et al., 2016).

The obtained soil hydraulic parameters, parameters of the water stress function of the FJ model, and root system parameters of the $\mathrm{C}$ model are listed in Table 4. The corresponding hydraulic conductivity curves are plotted in Fig. S1 in the Supplement. For the stony soil, the soil hydraulic parameters estimated by the two models were comparable but larger differences between the model parameters were obtained for the subsoil layer of the silty soil. Smaller (even negative) tortuosity parameters $l$ were obtained for silty than for the stony soil which implies that in the latter the hydraulic conductivities decrease more strongly, with a decrease in saturation degree (Eq. 13). For the same water content, hydraulic conductivities were higher in the stony than in the silty soil.

For the FJ model, parameters of the stress function were similar for the stony and silty plots, which implies that the estimated parameters were not sensitive to the different root densities in the two different soils. It is important to note that the difference in root density between the different water treatments in one soil was not considered in the model since only one parameter set was used to simulate the different water treatments. The obtained threshold values of the stress function $\alpha_{\mathrm{F}}, h_{31}$, and $h_{3 \mathrm{~h}}$ in Eq. (8) were higher than the lowest SWPs measured and simulated in the top- and subsoil layer in the sheltered and rainfed plots of the stony soil. Consequently, the FJ model simulated a reduction in RWU due to reduced water availability in these plots (Fig. 5b). For the silty soil, $h_{31}$ and $h_{3 \mathrm{~h}}$ were also higher than the lowest SWPs measured in the topsoil layer but lower than the SWPs in the subsoil. However, despite the lower SWPs in the topsoil and the low compensatory uptake (high $\omega_{\mathrm{c}}$ ), no reduction in transpiration rate was simulated in the silty soil (Fig. 6b) as compared to the calculated potential transpiration rate. A first explanation for this observation is that the high root density in the subsoil caused most of the water to be simulated as being taken from the subsoil where SWP was high. Therefore, a reduction of uptake in the top layer where root densities were low would not affect the total uptake considerably and would require only a small compensatory uptake from the subsoil. Albasha et al. (2015) noted that compensatory water uptake could also be caused by increased root growth in soil layers where more water is available. The second explanation is that the simulated SWP in the topsoil layer remained higher than corresponding measured values, which is another reason why no reduction in transpiration was simulated in the silty soil.

The values of $\omega_{\mathrm{c}}$ estimated by the FJ model were close to 1 for the three plots in both soils, which was consistent with the speculation given by Šimůnek and Hopmans (2009) that the compensatory ability of culture crops was limited. However, according to Jarvis (2011), based on the work of De Jong van Lier et al. (2008) and Jarvis (2010), $\omega_{\mathrm{c}}$ should depend on both root and plant properties (e.g., total root length, LAI, and unstressed stomatal conductance) that control $T_{\text {pot }}$. The value of $\omega_{\mathrm{c}}$ should be higher (low uptake compensation) for a lower ratio of total root length to LAI. For the silty soil, the ratios were similar in the three plots since there was not much difference in total root length and LAI among the three plots compared with those in the stony soil (Figs. 2a and 3). For the stony soil, the ratios of total root length to LAI deviated after 21 May (data no shown), being higher in the sheltered plots and lower in the irrigated plot, which indicated that theoretically $\omega_{\mathrm{c}}$ would be lower in the sheltered plot and higher in the irrigated plot. However, since fitting the parameters of the FJ model using data from a plot in which no water stress 

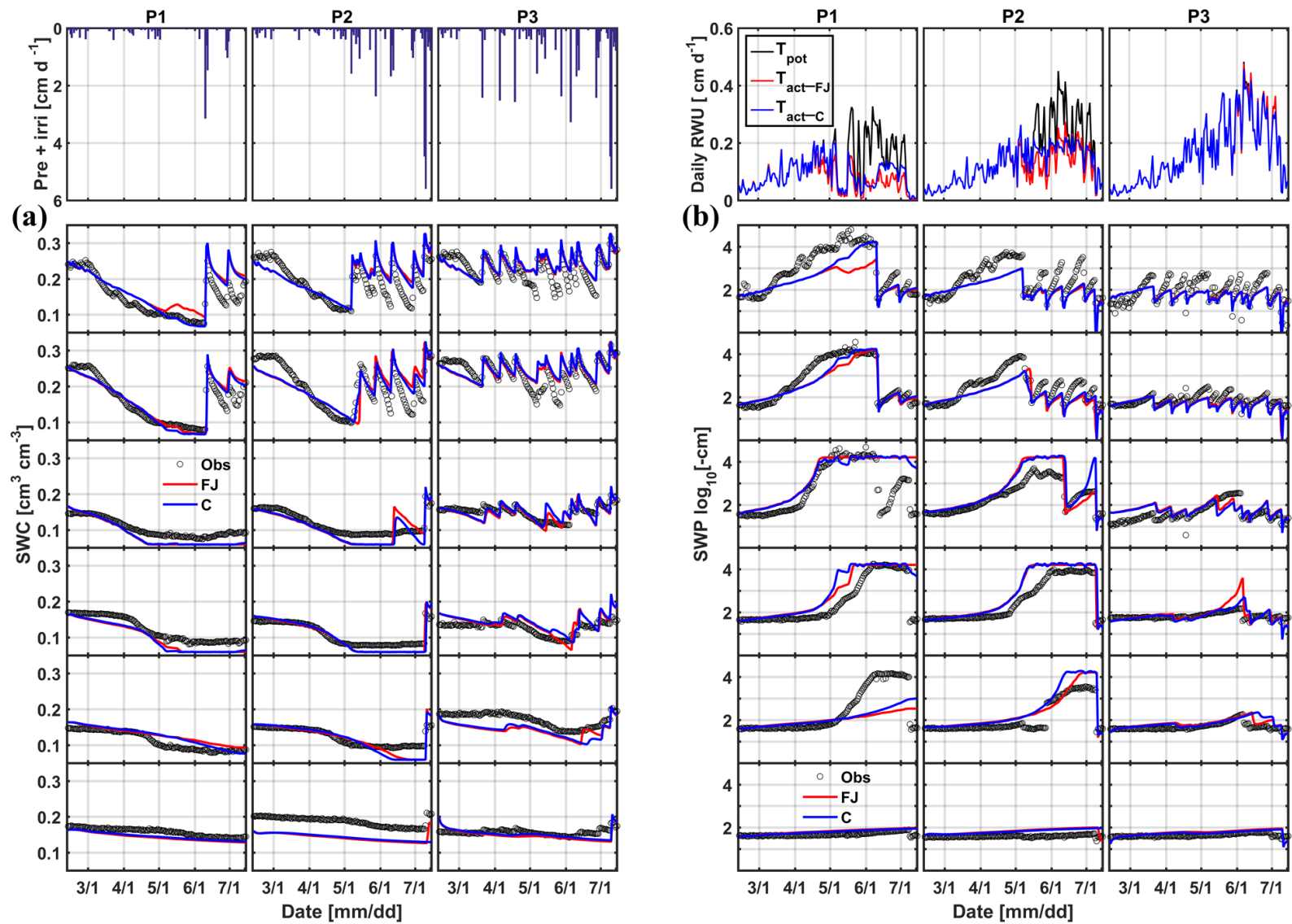

(b)

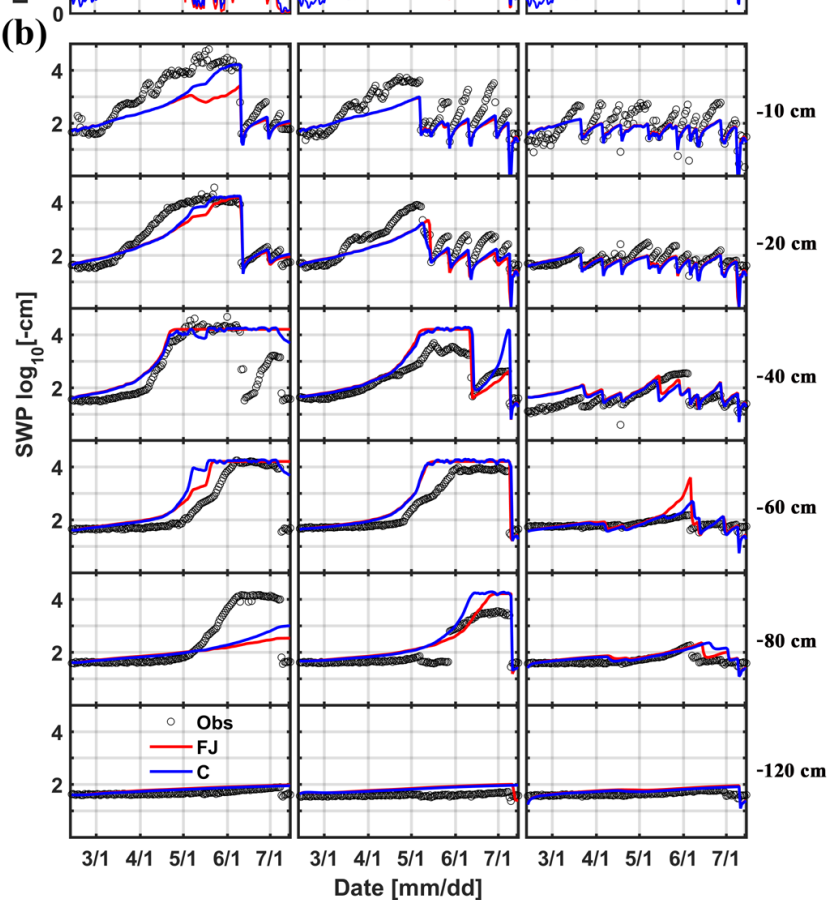

Figure 5. Comparison between observed (black) and simulated (a) soil water content (SWC) and (b) soil water pressure head (SWP) by the Feddes-Jarvis (FJ) and Couvreur (C) models at six soil depths in the sheltered (P1), rainfed (P2), and irrigated (P3) plots of the stony soil (F1) from 11 February to 14 July 2014 . Time series of precipitation (Pre) and irrigation (irri) and of the potential daily potential ( $\left.T_{\text {pot }}\right)$ and actual transpiration $\left(T_{\mathrm{act}}=\mathrm{RWU}\right)$ that were simulated by the Feddes-Jarvis (FJ) and Couvreur $(\mathrm{C})$ models are given in the panels above the SWC and SWP measurements.

Table 4. The saturated hydraulic conductivity $\left(K_{\mathrm{S}}\right)$, model shape parameter $(l)$, critical pressure head in the Feddes water stress function $\left(h_{31}, h_{3 \mathrm{~h}}\right)$, the compensation parameter $\left(\omega_{\mathrm{c}}\right)$, and the root system related parameters $\left(K_{\mathrm{rs}}\right.$ and $\left.K_{\text {comp }}\right)$ estimated by the Feddes-Jarvis $(\mathrm{FJ})$ and Couvreur (C) models of the stony (F1) and silty (F2) soils and the corresponding objective function (OF) values.

\begin{tabular}{|c|c|c|c|c|c|c|c|c|c|c|c|}
\hline Site & Model & $\begin{array}{r}K_{\mathrm{s} 1} \\
\left(\mathrm{cmh}^{-1}\right)\end{array}$ & $\begin{array}{r}l_{1} \\
(-)\end{array}$ & $\begin{array}{r}K_{\mathrm{s} 2} \\
\left(\mathrm{~cm} \mathrm{~h}^{-1}\right)\end{array}$ & $\begin{array}{r}l_{2} \\
(-)\end{array}$ & $\begin{array}{r}h_{31} \\
(\mathrm{~cm})\end{array}$ & $\begin{array}{r}h_{3 \mathrm{~h}} \\
(\mathrm{~cm})\end{array}$ & $\begin{array}{l}\omega_{\mathrm{c}} \\
(-)\end{array}$ & $\begin{array}{r}K_{\text {rs_ini }}^{*} \\
\left(\mathrm{~cm} \mathrm{~h}^{-1}\right)^{\mathrm{a}}\end{array}$ & $\begin{array}{l}K_{\text {comp_ini }}^{*} \\
\left(\mathrm{~cm} \mathrm{~h}^{-1}\right)\end{array}$ & $\mathrm{OF}$ \\
\hline \multirow[t]{4}{*}{ F1 } & FJ & 0.663 & 4.669 & 1.581 & 3.459 & -694 & -238 & 0.95 & - & - & 33.42 \\
\hline & & $(3.417)^{b}$ & $(1.470)$ & $(0.026)$ & $(-2.797)$ & $(-1172)$ & $(-648)$ & $(0.8)$ & & & (41.79) \\
\hline & $\mathrm{C}$ & 0.426 & 3.773 & 1.556 & 3.947 & - & - & - & $1.20 \times 10^{-7}$ & $3.89 \times 10^{-8}$ & 33.40 \\
\hline & & (3.853) & (1.472) & $(0.021)$ & $(-2.892)$ & & & & $\left(1.26 \times 10^{-7}\right)$ & $\left(3.74 \times 10^{-8}\right)$ & (40.97) \\
\hline \multirow[t]{2}{*}{$\mathrm{F} 2$} & FJ & 0.450 & -1.358 & 0.144 & -3.165 & -747 & -279 & 0.95 & - & - & 31.93 \\
\hline & $\mathrm{C}$ & 0.417 & -2.219 & 0.623 & 1.379 & - & - & - & $8.60 \times 10^{-8}$ & $4.77 \times 10^{-9}$ & 35.90 \\
\hline
\end{tabular}

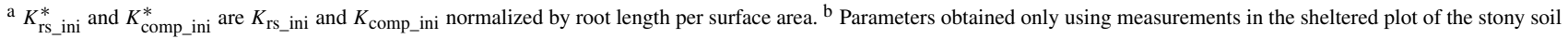
(Cai et al., 2017).

is observed is very difficult, and since the parameters of the FJ model could not be uniquely identified using inverse modeling also when data from water-stressed plots were used, we could neither confirm nor falsify the discussed relation between $\omega_{\mathrm{c}}$, root length, and LAI.

Temporal changes in root system hydraulic conductance $K_{\mathrm{rs}}$ of the $\mathrm{C}$ model are illustrated in Fig. 7 for the stony and 

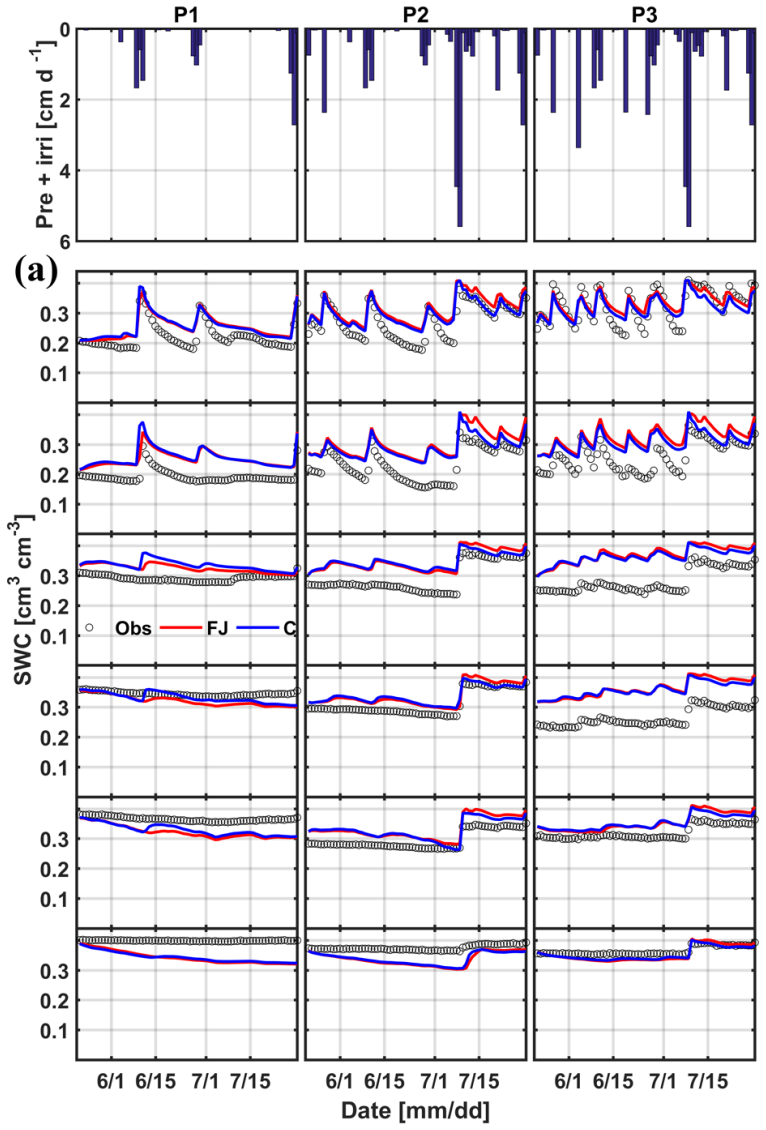

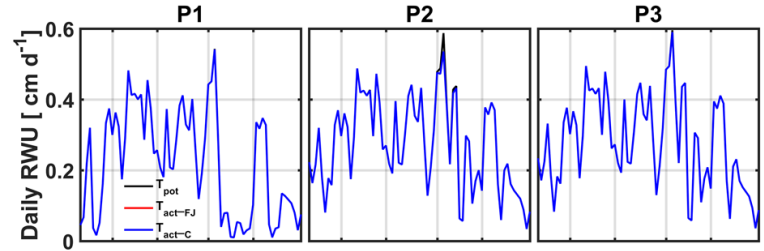

(b)

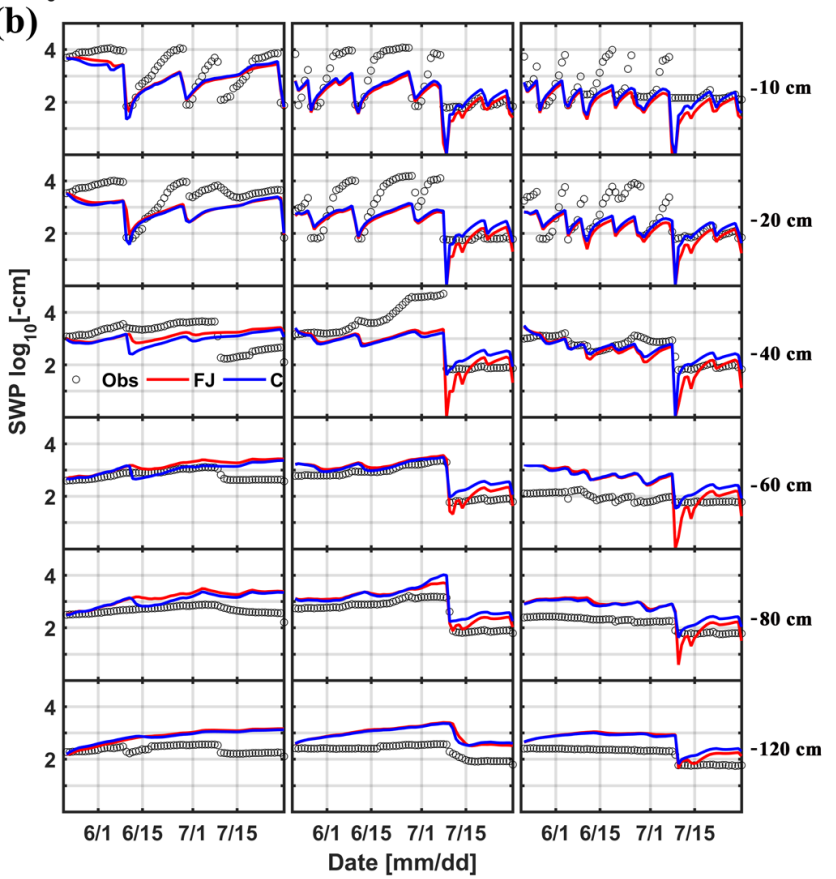

Figure 6. Same as Fig. 5 but for silty soil from 22 May to 30 July 2014.

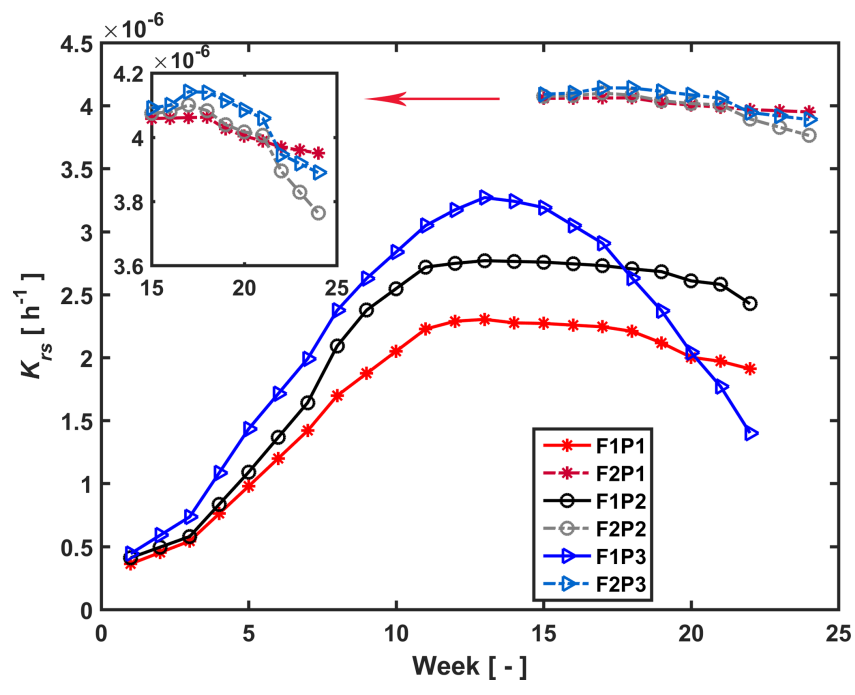

Figure 7. Estimated root hydraulic conductance $\left(K_{\mathrm{rs}}\right)$ in the three plots (P1: sheltered; P2: rainfed; P3: irrigated) of the stony (F1) and silty (F2) soils during the measurement period (F1: from 11 February to 11 July 2014, F2: from 23 May to 24 July 2014). silty soils. The $K_{\mathrm{rs}}$ values in the different plots of the same soil were calculated using the same fitted initial $K_{\mathrm{rS} \_ \text {ini }}$ and RLDs; therefore the difference in $K_{\mathrm{rs}}$ between the different plots of the same soil reflected differences in RLD. However, $K_{\mathrm{rs} \_ \text {ini }}$ was fitted independently for the two different soil types. The higher $K_{\mathrm{rs}}$ obtained for the silty soil with the higher root density than the stony soil supports our hypothesis that the root system hydraulic conductance increases with the RLD. Considering the root system conductance that was normalized by the root length per soil surface area, the normalized root conductance was different for the two different soils. The value of the normalized $K_{\text {rs_ini }}$ was 1.4 times larger and normalized $K_{\text {comp_ini }} 8.2$ times larger in the stony than in the silty soil. This indicated that for a single root segment the root conductance and compensatory ability was higher in the stony soil than in the silty soil. This difference does not support our assumption that $K_{\mathrm{rs}}$ is directly proportional to the RLD. It indicates that the different development of the root system in the stony soil, in which more water stress occurred, had an impact on the root hydraulic conductance of individual root segments.

To evaluate the uniqueness of the estimated parameters of the FJ and $\mathrm{C}$ models, response surfaces of the objective func- 
(a)
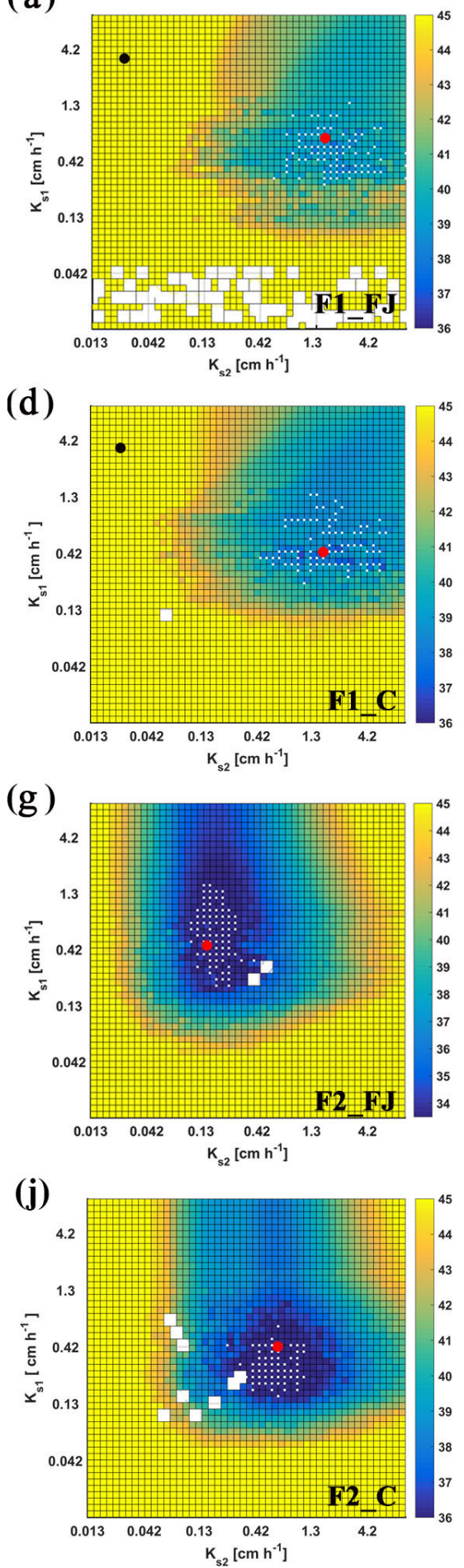

(b)
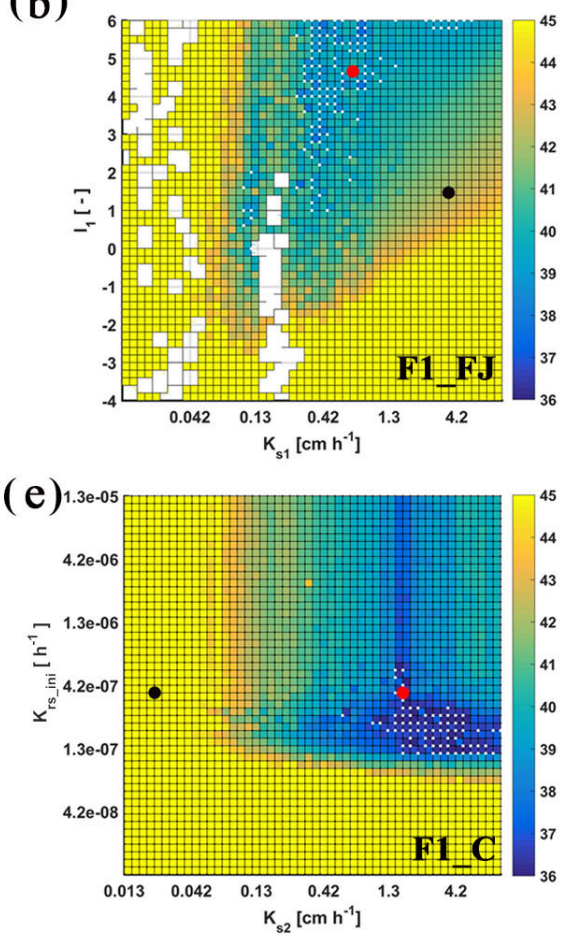

(h)
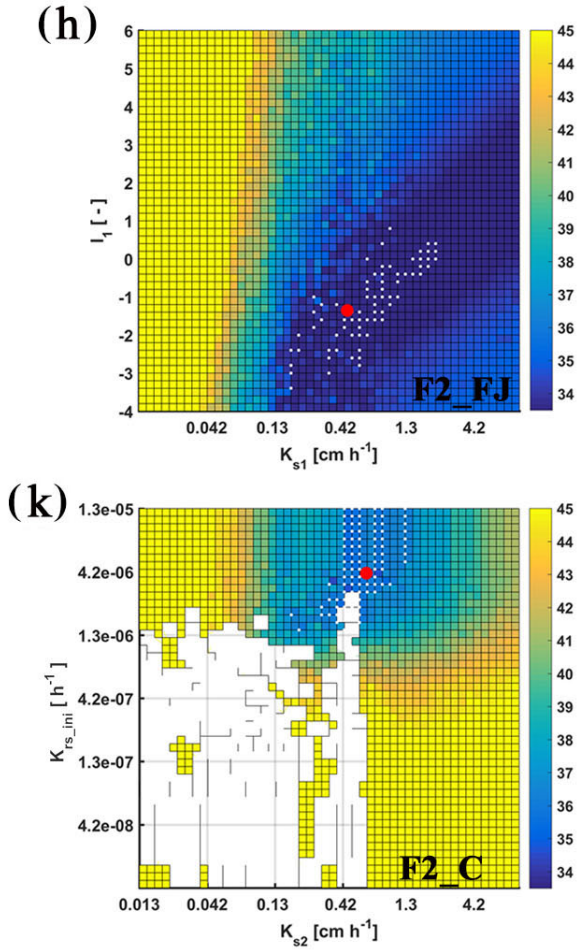

(c)
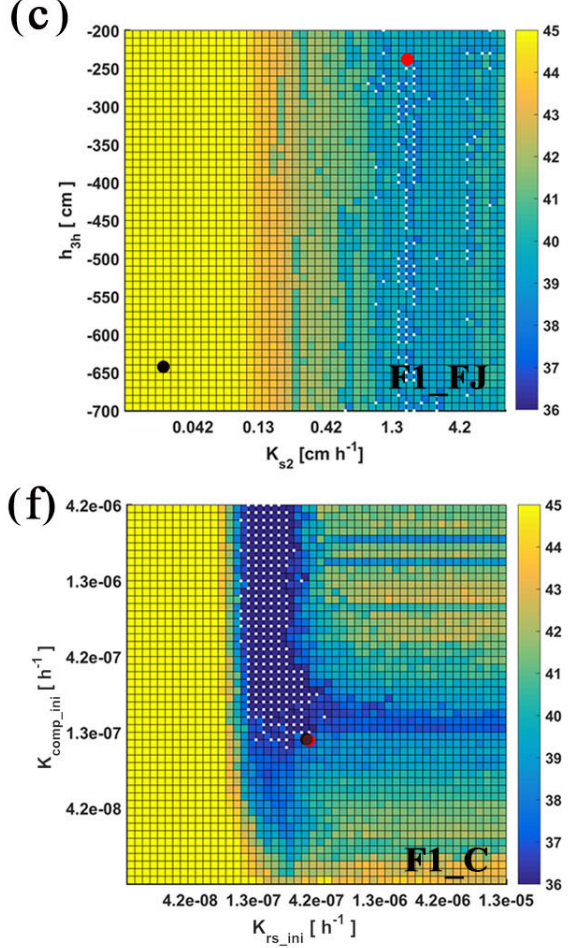

(i)
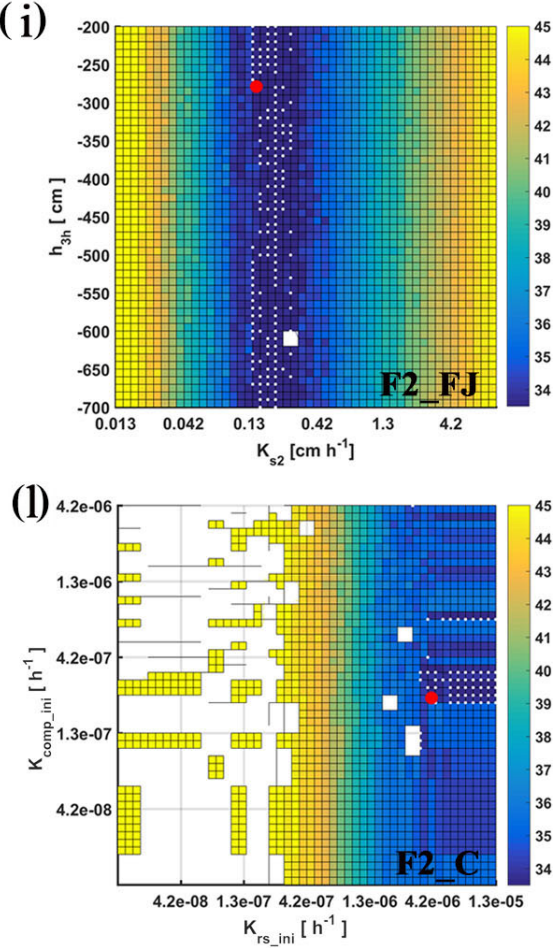

Figure 8. Response surface for $K_{\mathrm{s} 2}-K_{\mathrm{S} 1}\left(\mathrm{FJ}\right.$, Feddes-Jarvis model), $K_{\mathrm{S} 1}-l_{1}(\mathrm{FJ}), K_{\mathrm{s} 2}-h_{3 \mathrm{~h}}(\mathrm{FJ}), K_{\mathrm{s} 2}-K_{\mathrm{S} 1}\left(\mathrm{C}\right.$, Couvreur model), $K_{\mathrm{s} 2}-K_{\mathrm{rs} \_ \text {ini }}$ (C), and $K_{\text {rs_ini }}-K_{\text {comp_ini }}$ (C) parameter planes of the stony (F1) and silty (F2) soils. The color bar shows the range of the objective function. White dot: area within $0.5 \%$ range of objective function (OF) minimum; red dot: optimum value obtained from the inverse modeling; black dot: optimum value obtained from the sheltered plot of the stony soil. $K_{\mathrm{S}}$ : saturated conductivity; $l$ : empirical model parameter; 1 and 2 : top- and subsoil; $K_{\mathrm{rs}}$ : root system conductance; $K_{\mathrm{comp}}$ : compensatory root water uptake (RWU) conductance; $h_{3 \mathrm{~h}}$ : water potential at high transpiration. 
tion were plotted. Selected contour plots in Fig. 8 show that the soil hydraulic parameters were identifiable. The parameters in the C model were also identifiable in both soils but $K_{\mathrm{rs}}$ and $K_{\text {comp }}$ in the silty soil could be less precisely identified than in the stony soil. When RWU is not reduced and remains equal to the potential transpiration, which was the case in the silty soil (see later), Eq. (6) states that $K_{\mathrm{rs}}$ can decrease without changing the RWU by decreasing $H_{\text {leaf }}$ until the $H_{\text {leaf }}$ reaches the critical leaf water potential. This explains why regions with low objective function values are bound by minimally possible $K_{\mathrm{rs}}$ values but not by maximally possible $K_{\mathrm{rs}}$ values in the silty soil. When RWU is lower than the potential transpiration, there is also a maximally possible $K_{\mathrm{rs}}$ value; therefore leaf water potentials still reach the critical leaf water potential during the simulation period. In agreement with what was found by Cai et al. (2017), the response surface did not show a distinct global minimum for the water stress parameters in the FJ model.

In contrast to the current study, Cai et al. (2017) inversely estimated the soil hydraulic parameters and parameters of the FJ and $\mathrm{C}$ models using only observations from the sheltered plot in the stony soil. Inclusion of data from the rainfed and irrigated plots had an impact on the optimized soil hydraulic parameters (see values in parentheses in Table 4), whereas similar values of the root hydraulic conductances $K_{\text {rs_ini }}$ and $K_{\text {comp_ini }}$ were obtained. Including data that represent the hydraulic behavior of the soil under wetter conditions led to higher estimates of the hydraulic conductivity of the subsoil under wet conditions but lower estimates of hydraulic conductivities in the topsoil and in the subsoil for drier conditions (see Fig. S1). Using the parameter set obtained by Cai et al. (2017) resulted in slightly better (e.g., for SWC, RMSE was 0.0057 and 0.0036 smaller for FJ and $\mathrm{C}$ models, and $d$ was 0.0257 and 0.0129 higher for $\mathrm{FJ}$ and $\mathrm{C}$ models) estimates of SWC and SWP in the sheltered plot but in an underestimation of the SWC and SWP in the rainfed and especially in the irrigated plot (see Fig. S2). This illustrates that soil hydraulic parameters that were obtained for a certain set of boundary conditions are not always transferable to other conditions. Combining experimental datasets that represent a wider range of boundary conditions is therefore preferable.

\subsection{Simulations of root water uptake and comparison with sap flow measurements}

The cumulative $\mathrm{ET}_{\mathrm{pot}}, T_{\mathrm{pot}}$, and RWU simulated by the FJ and $\mathrm{C}$ models in the three plots of stony and silty soils during the whole measurement period and during the overlapping period of measurements in both soils are shown in Fig. 9. The higher cumulative $\mathrm{ET}_{\text {pot }}$ in the stony plot than in the silty plots is simply due to the longer measurement period in the stony plot. The lower $\mathrm{ET}_{\text {pot }}$ in the sheltered plot results from the lower net radiation due to sheltering as compared to the neighboring unsheltered plots. The difference in cumulative $\mathrm{ET}_{\text {pot }}$ between the stony and silty soils during the overlapping measurement period results from different $K_{\mathrm{c}}$ values due to different times of ripening of the crop in the two soils (Table 1). The ratio $T_{\text {pot }} / \mathrm{ET}_{\text {pot }}$ was considerably smaller in the stony soil than in the silty soil since the early crop development stage, when the crop canopy was not fully covering the soil and the LAI was low, was not covered by the measurement period in the silty soil. Differences in LAI also explain the smaller $T_{\text {pot }} / \mathrm{ET}_{\text {pot }}$ ratio in the sheltered plot of the stony soil compared with the rainfed and irrigated plots of this soil and the larger $T_{\mathrm{pot}} / \mathrm{ET}_{\mathrm{pot}}$ in the silty than in the stony soil during the overlapping measurement period. This illustrates that the potential water uptake by the wheat crop from the sheltered plot of the stony soil differs substantially from that of the other plots due to a different crop development and LAI. Only in the sheltered and rainfed plots of the stony soil was the simulated $T_{\text {act }}$ or RWU reduced compared to the $T_{\text {pot }}$. In the silty plot, there was no reduction in simulated $T_{\text {act }}$ compared to $T_{\text {pot }}$, indicating that the calculated soil water supply in the root zone in the silty soil was sufficient for meeting the atmospheric demand.

Figure 10 shows potential and actual RWU simulated by the FJ and $\mathrm{C}$ models and sap flow in the three plots of the stony soil and the silty soil from 23 May to 6 July 2014 . When the measured sap flow was regressed against the simulated RWU by the two models, there was a good agreement between crop transpiration obtained from the sap flow measurements and model simulations with $r^{2}$ of 0.86 by the FJ model and 0.85 by the $C$ model. However, there was a constant offset of $0.05 \mathrm{~cm} \mathrm{~d}^{-1}$ between the sap flow measurements and the simulated RWU (Fig. 11). The observed sap flow and the simulated $T_{\text {act }}$ were both higher in the silty than in the stony soil. In the silty soil, the sap flow measurements did not differ considerably between the different water treatments, which was consistent with the simulated $T_{\text {act }}$ that was equal to $T_{\text {pot }}$. For the stony soil, the measured sap flow differed between the different water treatments, which was also consistent with the differences in simulated $T_{\text {act }}$.

There was, as far as we know, no similar comparison between sap flow and simulated RWU using field observations for wheat crop. Due to the "delicate anatomy of the walls of hollow wheat stems" (Langensiepen et al., 2014), it is challenging to install the sensors and measure the temperature variation of the thin wheat stalk with high time frequency for the field condition. Furthermore, spatial variation in environmental conditions that influence the sap flow in a single stem and variability in stem development lead to a considerable stem to stem variability in sap flow in which the average deviation from mean sap flow is quantified for the three different treatments shown in Fig. 10 (Chabot et al., 2005; Zhang et al., 2014). The simulated RWU was based on a chain of models linked with assumptions and preset parameterizations starting from the calculation of the potential crop evapotranspiration using the empirical FAO56 approach, its split into soil evaporation and transpiration as a function of LAI, and its reduction to actual transpiration as a function 

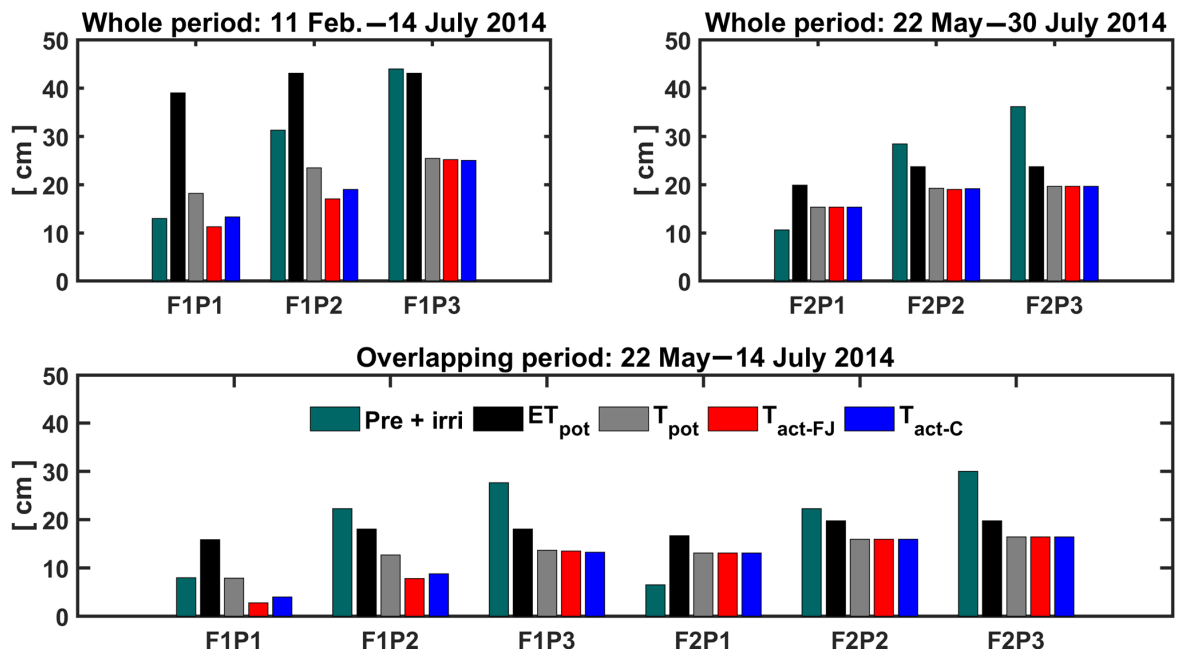

Figure 9. Potential evapotranspiration ( $\left.\mathrm{ET}_{\text {pot }}\right)$, potential transpiration $\left(T_{\text {pot }}\right)$, and actual transpiration $\left(T_{\text {act }}=\right.$ RWU) estimated by the FeddesJarvis (FJ) and Couvreur (C) models in the three plots (P1: sheltered; P2: rainfed; P3: irrigated) of the stony (F1) and silty (F2) soils in the whole period and in the overlapping period. Pre: precipitation; irri: irrigation.
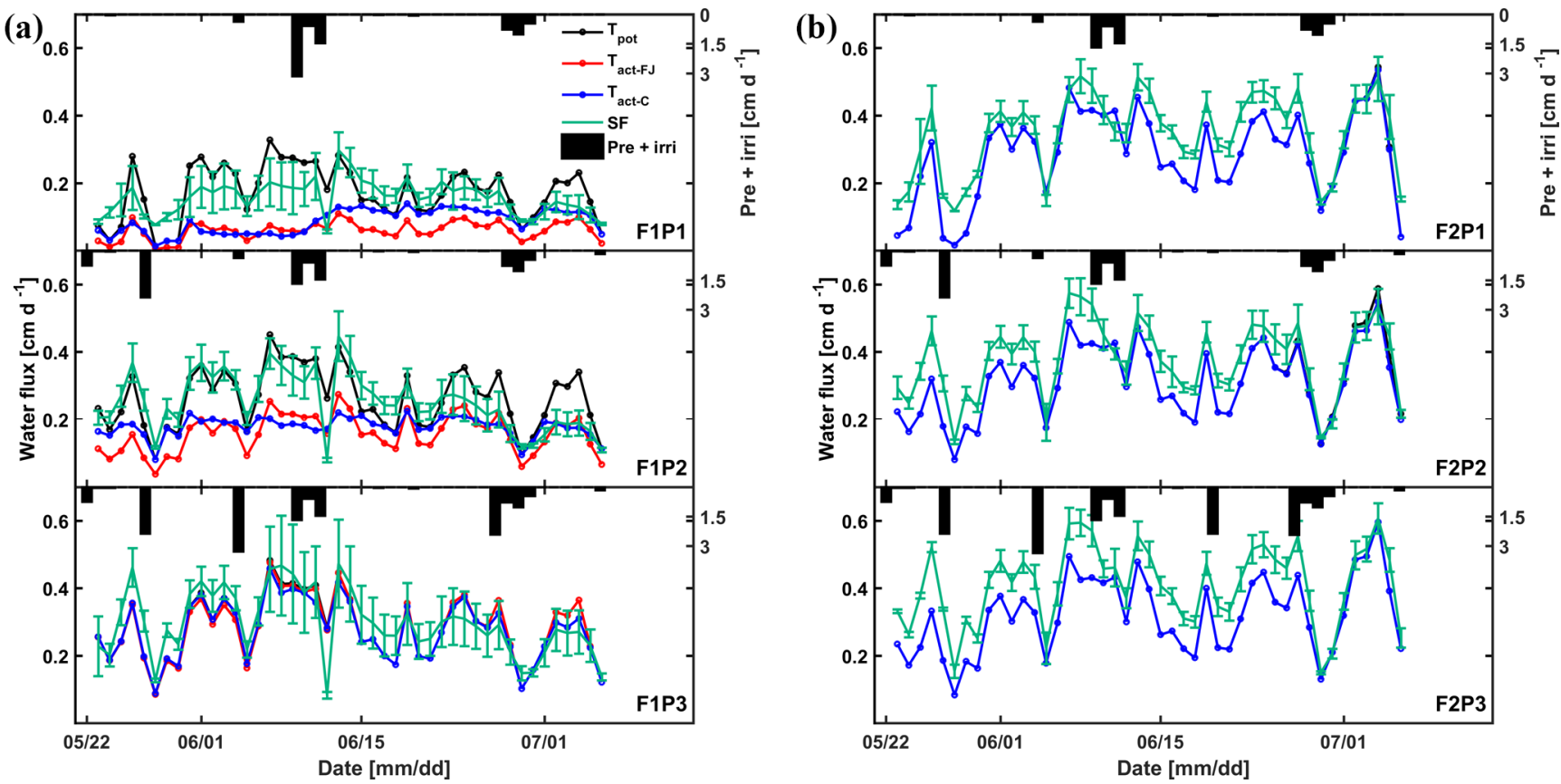

Figure 10. Daily cumulative potential transpiration $\left(T_{\mathrm{pot}}\right)$, root water uptake $\left(T_{\mathrm{act}}=\mathrm{RWU}\right)$ simulated by the Feddes-Jarvis $(\mathrm{FJ})$ and Couvreur (C) models, and sap flow (SF) in the three plots (P1: sheltered; P2: rainfed; P3: irrigated) of (a) the stony (F1) and (b) silty (F2) soils from 23 May to 6 July 2014. The curves of $T_{\text {pot }}, T_{\text {act-FJ }}$, and $T_{\text {act-C }}$ overlapped in (b). Pre: precipitation; irri: irrigation.

of soil water potential. The overall good correlation between simulated RWU and sap flow measured transpiration therefore gives some confidence in the used approaches.

In order to unravel the model's capability to calculate RWU in different soils and for different water treatments further, we made plots of the ratios of the measured sap flow in the two soils vs. the ratios of simulated RWU in the two soils for the different water treatments (Fig. 12). Ratios were used to cancel out the temporal variations due to varying meteorological conditions. The good agreement between measured and simulated ratios for the irrigated plots, in which RWU was not influenced by water availability, indicates that the differences in potential transpiration rates between the two plots due to different crop development (ripening) and LAI were adequately represented in the models. There is no difference between the FJ and C models since RWU is com- 


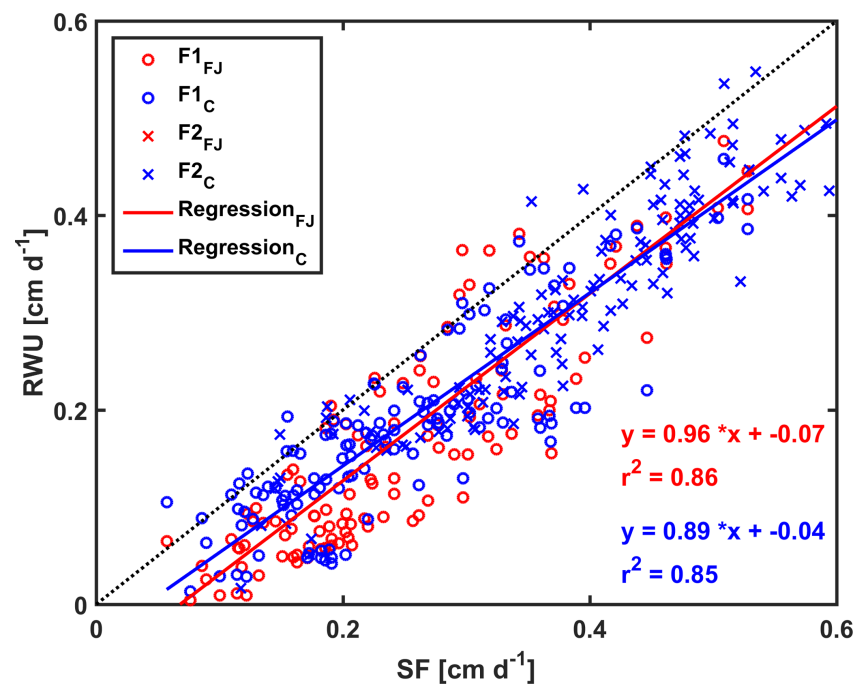

Figure 11. Correlation between sap flow (SF) and root water uptake (RWU) simulated by the Feddes-Jarvis (FJ) and Couvreur (C) models of the stony (F1) and silty (F2) soils. The crosses (x) obtained by the $\mathrm{FJ}$ and $\mathrm{C}$ models overlapped in $\mathrm{F} 2$.

pletely defined as a boundary condition and is not dependent on the soil water status in the irrigated plots, which was discussed by Cai et al. (2017). For the rainfed and sheltered plots, the correlation between the measured and simulated ratios is smaller. These ratios represent to what extent the simulated reduction of RWU in the stony soil due to reduced water availability is consistent with the measured reduction in sap flow relative to the simulated RWU and measured sap flow in the silty plots where there was no reduction in RWU. Of note is that simulations by the $\mathrm{C}$ model are more consistent with the sap flow measurements than the simulations by the FJ model. The ratios of the FJ model simulations vary less than the ratios of the sap flow measurements, whereas the range of ratios of the $\mathrm{C}$ model simulations is more in agreement with the sap flow measurements. This indicates that the $\mathrm{C}$ model represents how changing soil moisture and soil moisture distributions change the RWU better than the FJ model. Furthermore, since the root hydraulic conductance in the $\mathrm{C}$ model depends on the root density, the model can reflect the impact of the differences in root density between the different water treatments on RWU. The FJ model did not possess this flexibility since only one set of water stress parameters was used for the different water treatments. Similar observations were made by Vandoorne et al. (2012) who optimized the water stress parameters of the FJ model for chicory (Cichorium intybus L.) and found that the values of those parameters had to be adapted for different soil moisture conditions and different plant growth stages.

Sap flow per unit soil surface area was obtained by multiplying the average sap flow in the measured tillers by the number of tillers per unit soil surface area. Figure 13 shows the average sap flow per tiller and the sap flow per unit leaf
Table 5. Cumulative root water uptake simulated by the Couvreur model using root hydraulic conductance $\left(K_{\mathrm{rs}}\right)$ obtained from the silty soil (F2) for the stony soil (F1) and using $K_{\mathrm{rs}}$ obtained from the stony soil for the silty soil. P1, P2, and P3 are the sheltered, rainfed, and irrigated plots. Values in parentheses are simulated RWU using the optimized parameters from measured SWC and SWP in the respective plots.

\begin{tabular}{rrrr}
\hline & P1 & P2 & P3 \\
\hline F1 & $13.55(13.27)$ & $19.38(19.01)$ & $25.40(25.02)$ \\
F2 & $14.04(15.36)$ & $17.40(19.12)$ & $17.96(19.65)$ \\
\hline
\end{tabular}

area index. For the silty soil, the sap flow per tiller and sap flow per leaf area were very similar for the different water treatments. For the stony soil, the sap flow per tiller in the irrigated plot was similar to that in the silty soil until approximately 15 June. After that, the sap flow per tiller reduced in the irrigated plot of the stony soil because of the reduction in leaf area (the sap flow per leaf area remained similar to that in the silty soil). Water stress limited the leaf development of wheat in both longevity and quantity (Khalid et al., 2016; Zhou et al., 2015). The sap flow per tiller in the rainfed plot of the stony soil became smaller than that in the irrigated plot or in the silty soil after 11 June but recovered for a short time period to the same sap flow after the rainfall on 10 June. This recovery was also observed for the sap flow in the sheltered plot of the stony soil. However, the sap flow per tiller was generally lower in this plot than in the other plots. This indicates that transpiration in this plot was reduced by both a reduced number of tillers and a lower flux per tiller. It is interesting to note that the sap flow per leaf area surface in the sheltered stony plot shortly increased to higher values than in other plots after the rainfall event on 10 June.

\subsection{Effects of root and shoot development on simulated transpiration}

The different root development in the two soils and for the different water treatments (Fig. 3) was related to a different parameterization of the root hydraulic conductance (Fig. 7). The different shoot development and different LAI values (Fig. 2a) affected calculations of potential transpiration rates (Fig. 9) that were used as boundary conditions for RWU simulations. In order to demonstrate the impact of the plant development on the RWU simulation, we conducted two sets of simulations in which the plant parameters were prescribed by measurements done in another soil and/or water treatment. In the first set of simulations, we changed the root hydraulic conductance, $K_{\mathrm{rs}}$. For the stony soil, $K_{\mathrm{rs}}$ values of all plots were rescaled by a factor of 1.78 , which corresponds to the ratio of $K_{\mathrm{rs}}$ in the sheltered plot of the silty soil in week 15 to $K_{\mathrm{rs}}$ in the sheltered plot of the stony soil in the same week. This rescaling represents how RWU would change if the plants did not reduce the root hydraulic conductance in 

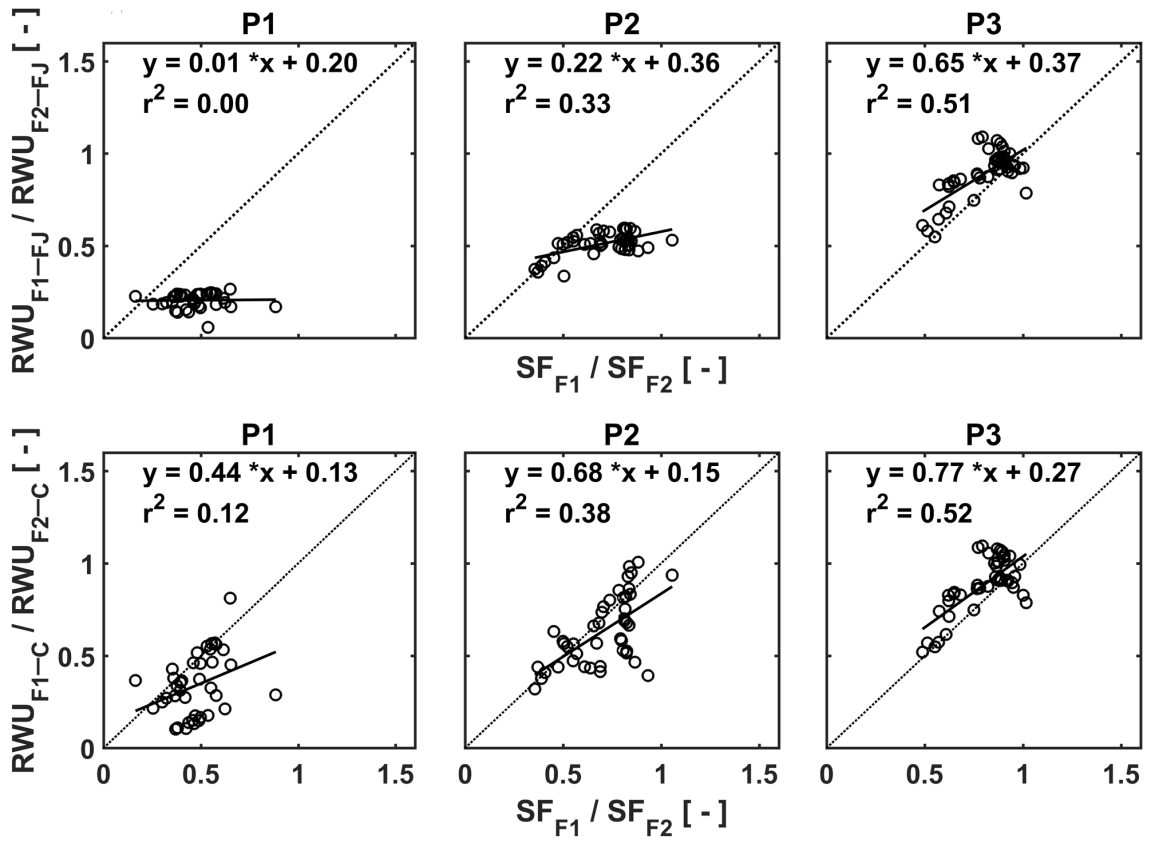

Figure 12. Relation between the ratio of the RWU in the stony soil to the RWU in the silty soil estimated by the FJ and C models in the three plots (P1: sheltered; P2: rainfed; P3: irrigated) and the ratio of sap flow in the stony soil (F1) to that in the silty soil (F2).

the stony soil. For the silty soil, $K_{\mathrm{rs}}$ was scaled by a factor of 0.56 , which is the inverse of the factor used to scale the root conductance in the stony plot. The rescaling for the silty plot represents how water uptake in the silty soil would be reduced if the root conductance were equal to that in the sheltered plot of the stony soil. For the stony plot, rescaling (i.e., increasing) the root conductance only increased the cumulative water uptake by about $2 \%$ in all plots (see Table 5). Increasing the root conductance therefore did not increase the amount of water that could be extracted from the stony soil substantially. For the silty soil, rescaling (i.e., decreasing) the root conductance in fact generated water stress and reduced the RWU by $9 \%$. Therefore, the root system with higher root densities and conductance in silty soil is apparently not "over-dimensioned", whereas increasing the root conductance in the stony soil would hardly lead to more water uptake.

In a second set of simulations, we changed the calculated potential transpiration of the sheltered stony plot to that of the irrigated stony plot (Fig. 14). Only the stony soil was considered since the shoot and LAI development did not differ considerably between the different water treatments in the silty plot. Until 1 May, there was almost no difference in the LAI and $T_{\text {pot }}$ among different plots; therefore there was also no big effect on the simulated $T_{\text {act }}$. $T_{\text {pot }}$ in the irrigated plot started to deviate from $T_{\text {pot }}$ in the sheltered plot from 1 May due to higher LAI in the irrigated plot (Fig. 2a). Increasing $T_{\text {pot }}$ in the sheltered plot did not affect the simulated RWU by the $\mathrm{C}$ model. In this model, the boundary condition switches to a constant pressure head boundary condition when stress occurs; therefore the simulated root water becomes independent of the potential transpiration rate.

Of interest is also the time at which water uptake starts to decrease and its effect on plant development. In the sheltered and rainfed stony plots, a slight reduction in RWU is simulated during April. This reduction in RWU was accompanied by only a slight decrease in LAI development compared to the irrigated plot (Fig. 2a). After the middle of May, which is also the period when RWU reduced more strongly, the LAI did not increase anymore in the sheltered plots, whereas in the other plots of the stony soil, it reached its maximum at the beginning of June. In the silty soil, the maximum was reached at the beginning of July. The root system reached its full development, however, earlier than the time when the LAI reached its maximum (Fig. 3). The root system development in the stony plot was much more strongly reduced by the lower water availability in April than the LAI development. Both leaves and roots showed reactions to environmental changes but these reactions were not simultaneous. Walter and Schurr (2005) reviewed studies of leaf and root growth of herbaceous plants and indicated that roots experienced the effect of environmental factors (i.e., water stress, nutrient deficiency) more directly compared with leaves. They also indicated that roots responded faster than leaves to the environmental conditions to optimize resource use efficiency. 
(a)

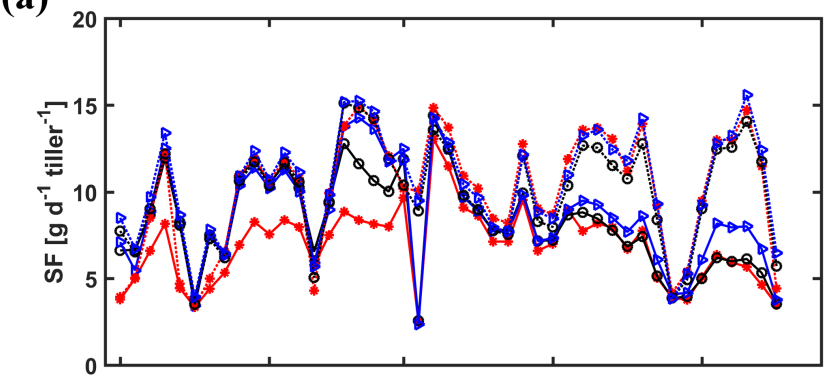

(b)

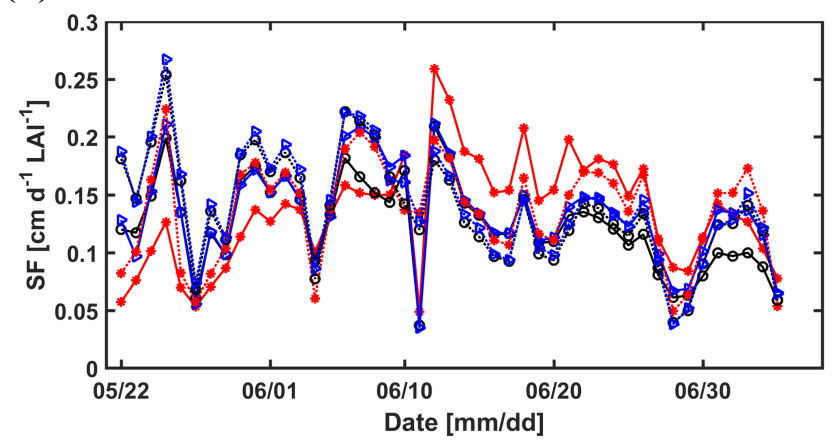

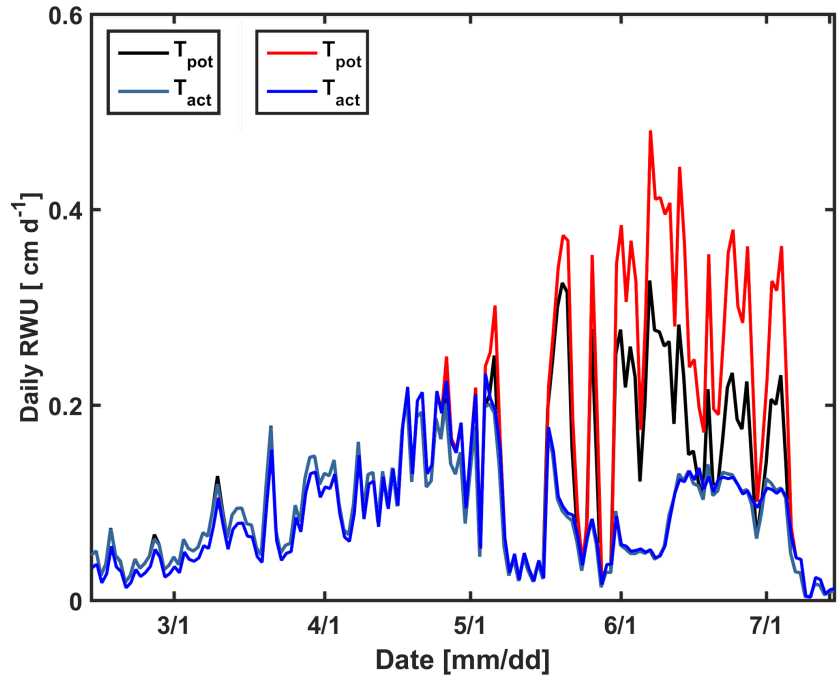

Figure 14. Daily potential $\left(T_{\mathrm{pot}}\right)$ and actual transpiration $\left(T_{\text {act }}=\right.$ RWU) estimated by the Couvreur model using the measured leaf area index (LAI) in the sheltered plot (black and cyan) of the stony soil and the LAI in the irrigated plot of the stony soil (red and blue).

root system that developed in the stony soil would be underdimensioned for the silty soil and the opposite for the root system that developed in the silty soil. It also suggests that considering the link between root conductance and total root length gave the model extra flexibility to describe root water uptake for different scenarios of root water availability (both due to different soil types and water treatments). Therefore, when using the $\mathrm{C}$ model, in addition to the information about rooting depth and relative root density distributions, information about the total root length is also directly used to describe the temporal evolution of the root system conductance in different soils and for different water treatments.

The simulated differences in transpiration from the two different soils and the different water treatments could be confirmed by sap flow measurements. The physically based $\mathrm{C}$ model predicted the ratios of the transpiration fluxes in the two soil types slightly better than the FJ model. Since the transpiration from the silty soil was close to $T_{\text {pot }}$, these ratios represented to what extent the transpiration was reduced due to reduced water availability in the stony soil.

This study illustrated that a combined dataset of root and shoot development, of soil water contents and soil water potentials, and of transpiration fluxes derived from sap flow measurements can be used to parameterize and validate RWU models. These models require inputs from root and shoot developments, which were observed to depend strongly on the environmental conditions. How far the $\mathrm{C}$ model can improve prediction of RWU, transpiration, and soil water stock depletion in widely used crop models for different crops and climate conditions is the subject of further investigations. Next to improving the description of the 
RWU, the $\mathrm{C}$ model also simulates the water potential in the root collar. In the current model formulation, the water potential in the collar is used as a control variable which is kept fixed when a critical threshold value is reached. We interpreted the reduction in transpiration when this threshold was reached as water stress. However, we observed considerable reduction in aboveground biomass even when no reduction in transpiration was simulated (or observed with sap flow measurements), e.g., in the sheltered and rainfed silty soil plots. Next to transpiration, stomatal opening, and carbon assimilation, plant growth is also linked to the hydraulic status of the shoot (Tardieu et al., 2014). Predictions of the shoot water potential, which is closely linked to the water potential in the root collar, using models that simulate water fluxes in the soil-plant-atmosphere system, provide information for growth models that simulate the reaction of plant growth to environmental conditions related to drought stress. Therefore, linking growth and water flux models is important for understanding and predicting the interactions between plant growth and soil water availability.

Concerning the observations of the root development using horizontally rhizotubes, it needs to be further investigated how root counts along rhizotubes can be translated to root densities. Also, the reasons for the constant offset between the simulated transpiration and the sap flow measurements need to be investigated further.

Data availability. The meteorological data that were obtained from a climate station located in Selhausen (Germany) are freely available on the TERENO data portal (http://www.tereno.net; Schmidt, 2014). The data that were measured in the rhizotron facilities are available from the corresponding author on reasonable request and with permission of the Institute of Bio- and Geosciences (IBG-3), Forschungszentrum Jülich.

Supplement. The supplement related to this article is available online at: https://doi.org/10.5194/hess-22-2449-2018-supplement.

Competing interests. The authors declare that they have no conflict of interest.

Acknowledgements. This study was financially supported by SFB/TR 32 (Transregional Collaborative Research Centre 32, funded by the Deutsche Forschungsgemeinschaft (DFG)). The meteorological data were obtained from the online database of the project TERENO. The rhizotron facility is part of the TERENO network of terrestrial observatories. The authors thank the reviewers for their valuable comments and suggestions to improve the manuscript.

The article processing charges for this open-access publication were covered by a Research
Centre of the Helmholtz Association.

Edited by: Nunzio Romano

Reviewed by: two anonymous referees

\section{References}

Albasha, R., Mailhol, J.-C., and Cheviron, B.: Compensatory uptake functions in empirical macroscopic root water uptake models experimental and numerical analysis, Agr. Water Manage., 155, 22-39, https://doi.org/10.1016/j.agwat.2015.03.010, 2015.

Allen, R. G., Jensen, M. E., Wright, J. L., and Burman, R. D.: Operational estimates of reference evapotranspiration, Agron J., 81, 650-662, 1989.

Allen, R. G., Pereira, L. S., Raes, D., and Smith, M.: Crop Evapotranspiration - Guidelines for Computing Crop Water Requirements - FAO Irrigation and Drainage paper 56, FAO, Rome, 300, 6541, 1998.

Amenu, G. G. and Kumar, P.: A model for hydraulic redistribution incorporating coupled soil-root moisture transport, Hydrol. Earth Syst. Sci., 12, 55-74, https://doi.org/10.5194/hess-12-55-2008, 2008.

Bechmann, M., Schneider, C., Carminati, A., Vetterlein, D., Attinger, S., and Hildebrandt, A.: Effect of parameter choice in root water uptake models - the arrangement of root hydraulic properties within the root architecture affects dynamics and efficiency of root water uptake, Hydrol. Earth Syst. Sci., 18, 4189-4206, https://doi.org/10.5194/hess-18-4189-2014, 2014.

Bingham, I. J., Walters, D. R., Foulkes, M. J., and Paveley, N. D.: Crop traits and the tolerance of wheat and barley to foliar disease, Ann. Appl. Biol., 154, 159-173, https://doi.org/10.1111/j.17447348.2008.00291.x, 2009.

Brandyk, T. and Wesseling, J. G.: Steady state capillary rise in some soil profiles, Z. Pflanz. Bodenkunde, 148, 54-65, https://doi.org/10.1002/jpln.19851480107, 1985.

Bunce, J. A.: Effects of water stress on leaf expansion, net photosynthesis, and vegetative growth of soybeans and cotton, Can. J. Bot., 56, 1492-1498, 1978.

Cai, G., Vanderborght, J., Klotzsche, A., van der Kruk, J., Neumann, J., Hermes, N., and Vereecken, H.: Construction of minirhizotron facilities for investigating root zone processes, Vadose Zone J., 15, https://doi.org/10.2136/vzj2016.05.0043, 2016.

Cai, G., Vanderborght, J., Couvreur, V., Mboh, C. M., and Vereecken, H.: Parameterization of Root Water Uptake Models Considering Dynamic Root Distributions and Water Uptake Compensation, Vadose Zone J., 17, https://doi.org/10.2136/vzj2016.12.0125, 2018.

Cermak, J., Kucera, J., and Nadezhdina, N.: Sap flow measurements with some thermodynamic methods, flow integration within trees and scaling up from sample trees to entire forest stands, TreesStruct. Funct., 18, 529-546, https://doi.org/10.1007/s00468-0040339-6, 2004.

Chabot, R., Bouarfa, S., Zimmer, D., Chaumont, C., and Moreau, S.: Evaluation of the sap flow determined with a heat balance method to measure the transpiration of a sugarcane canopy, Agr. Water Manage., 75, 10-24, https://doi.org/10.1016/j.agwat.2004.12.010, 2005. 
Cohen, Y., Takeuchi, S., Nozaka, J., and Yano, T.: Accuracy of sap flow measurement using heat balance and heat pulse methods, Agron J., 85, 1080-1086, 1993.

Couvreur, V., Vanderborght, J., and Javaux, M.: A simple threedimensional macroscopic root water uptake model based on the hydraulic architecture approach, Hydrol. Earth Syst. Sci., 16, 2957-2971, https://doi.org/10.5194/hess-16-2957-2012, 2012.

Couvreur, V., Vanderborght, J., Beff, L., and Javaux, M.: Horizontal soil water potential heterogeneity: simplifying approaches for crop water dynamics models, Hydrol. Earth Syst. Sci., 18, 17231743, https://doi.org/10.5194/hess-18-1723-2014, 2014a.

Couvreur, V., Vanderborght, J., Draye, X., and Javaux, M.: Dynamic aspects of soil water availability for isohydric plants: focus on root hydraulic resistances, Water Resour. Res., 50, 8891-8906, https://doi.org/10.1002/2014wr015608, 2014b.

De Jong van Lier, Q., Van Dam, J., Metselaar, K., De Jong, R., and Duijnisveld, W.: Macroscopic root water uptake distribution using a matric flux potential approach, Vadose Zone J., 7, 10651078, https://doi.org/10.2136/vzj2007.0083, 2008.

Doussan, C., Pagès, L., and Vercambre, G.: Modelling of the hydraulic architecture of root systems: an integrated approach to water absorption-model description, Ann. Bot., 81, 213-223, https://doi.org/10.1006/anbo.1997.0540, 1998.

Doussan, C., Pierret, A., Garrigues, E., and Pagès, L.: Water uptake by plant roots: II - modelling of water transfer in the soil root-system with explicit account of flow within the root system - comparison with experiments, Plant Soil, 283, 99-117, https://doi.org/10.1007/s11104-004-7904-z, 2006.

Dynamax: Dynagage Sap Flow Sensor User Manual, available at: http://dynamax.com/images/uploads/papers/Dynagage_ Manual.pdf (last access: 29 June 2017), 2009.

Feddes, R. A., Kowalik, P., Kolinskamalinka, K., and Zaradny, H.: Simulation of field water uptake by plants using a soil water dependent root extraction function, J. Hydrol., 31, 13-26, https://doi.org/10.1016/0022-1694(76)90017-2, 1976.

Fitter, A. H., Graves, J. D., Self, G. K., Brown, T. K., Bogie, D. S., and Taylor, K.: Root production, turnover and respiration under two grassland types along an altitudinal gradient: influence of temperature and solar radiation, Oecologia, 114, 20-30, https://doi.org/10.1007/s004420050415, 1998.

Garré, S., Javaux, M., Vanderborght, J., and Vereecken, H.: Three-dimensional electrical resistivity tomography to monitor root zone water dynamics, Vadose Zone J., 10, 412-424, https://doi.org/10.2136/vzj2010.0079, 2011.

Gong, D., Kang, S., Zhang, L., Du, T., and Yao, L.: A twodimensional model of root water uptake for single apple trees and its verification with sap flow and soil water content measurements, Agr. Water Manage., 83, 119-129, https://doi.org/10.1016/j.agwat.2005.10.005, 2006.

Granier, A., Huc, R., and Barigah, S.: Transpiration of natural rain forest and its dependence on climatic factors, Agr. Forest Meteorol., 78, 19-29, https://doi.org/10.1016/0168-1923(95)02252-x, 1996.

Green, S. and Clothier, B.: The root zone dynamics of water uptake by a mature apple tree, Plant Soil, 206, 61-77, https://doi.org/10.1023/a:1004368906698, 1998.

Groh, J., Vanderborght, J., Pütz, T., and Vereecken, H.: How to control the lysimeter bottom boundary to investigate the ef- fect of climate change on soil processes?, Vadose Zone J., 15, https://doi.org/10.2136/vzj2015.08.0113, 2016.

Heinen, M.: FUSSIM2: brief description of the simulation model and application to fertigation scenarios, Agronomie, 21, 285296, https://doi.org/10.1051/agro:2001124, 2001.

Howard, S., Ong, C., Black, C., and Khan, A.: Using sap flow gauges to quantify water uptake by tree roots from beneath the crop rooting zone in agroforestry systems, Agroforest. Syst., 35, 15-29, https://doi.org/10.1007/bf02345326, 1996.

Huber, B.: Beobachtung und Messung pflanzlicher Saftströme, Ber. Dtsch. Bot. Ges., 50, 89-109, 1932.

Jaeger, L. and Kessler, A.: Twenty years of heat and water balance climatology at the Hartheim Pine Forest, Germany, Agr. Forest Meteorol., 84, 25-36, https://doi.org/10.1016/s01681923(96)02372-6, 1997.

Jarvis, N.: A simple empirical model of root water uptake, J. Hydrol., 107, 57-72, https://doi.org/10.1016/0022-1694(89)900504, 1989

Jarvis, N.: Comment on "Macroscopic root water uptake distribution using a matric flux potential approach", Vadose Zone J., 9, 499-502, https://doi.org/10.2136/vzj2009.0148, 2010.

Jarvis, N. J.: Simple physics-based models of compensatory plant water uptake: concepts and eco-hydrological consequences, Hydrol. Earth Syst. Sci., 15, 3431-3446, https://doi.org/10.5194/hess-15-3431-2011, 2011.

Javaux, M., Schröder, T., Vanderborght, J., and Vereecken, H.: Use of a three-dimensional detailed modeling approach for predicting root water uptake, Vadose Zone J., 7, 1079-1088, https://doi.org/10.2136/vzj2007.0115, 2008.

Khalid, M., Afzal, F., Gul, A., Ahanger, M. A., and Ahmad, P.: Analysis of novel haplotype variation at TaDREBD1 and TaCwi-D1 genes influencing drought tolerance in bread/synthetic wheat derivatives, in: Water Stress and Crop Plants, John Wiley \& Sons, Ltd, 206-226, 2016.

Knaps, A.: Klimastatistik: Jahresmittelwerte von 1961-2015, available at: http://www.fz-juelich.de/gs/DE/UeberUns/Organisation/ S-U/Meteorologie/klima/statistik_tabelle.html, last access: 26 October 2016.

Langensiepen, M., Kupisch, M., Graf, A., Schmidt, M., and Ewert, F.: Improving the stem heat balance method for determining sap-flow in wheat, Agr. Forest Meteorol., 186, 34-42, https://doi.org/10.1016/j.agrformet.2013.11.007, 2014.

Luo, Y., OuYang, Z., Yuan, G., Tang, D., and Xie, X.: Evaluation of macroscopic root water uptake models using lysimeter data, T. ASAE, 46, 625-634, 2003.

Mansfield, T. A. and Atkinson, C. J.: Stomatal behaviour in water stressed plants, in: Stress responses in plants: adaptation and acclimation mechanisms, edited by: Alscher, R. G. and Cumming, J. R., Wiley-Liss, New York, 241-264, 1990.

Massai, R. and Remorini, D.: Estimation of water requirements in a young peach orchard under irrigated and stressed conditions, in: Proceedings of the Third International Symposium on Irrigation of Horticultural Crops, Vols 1 and 2, edited by: Ferreira, M. I. and Jones, H. G., Acta Horticulturae, 537, 77-86, 2000.

Matsuo, N., Ozawa, K., and Mochizuki, T.: Genotypic differences in root hydraulic conductance of rice (Oryza sativa L.) in response to water regimes, Plant Soil, 316, 25-34, https://doi.org/10.1007/s11104-008-9755-5, 2009. 
Maurel, C., Simonneau, T., and Sutka, M.: The significance of roots as hydraulic rheostats, J. Exp. Bot., 61, 3191-3198, https://doi.org/10.1093/jxb/erq150, 2010.

Merotto Jr, A. and Mundstock, C.: Wheat root growth as affected by soil strength, Rev. Bras. Cienc. Solo, 23, 197-202, 1999.

Meyer, W. S. and Barrs, H. D.: Roots in irrigated clay soils: measurement techniques and responses to root zone conditions, Irrigation Sci., 12, 125-134, 1991.

Molz, F. J.: Models of water transport in the soilplant system: a review, Water Resour. Res., 17, 1245-1260, https://doi.org/10.1029/WR017i005p01245, 1981.

Mualem, Y.: A new model for predicting the hydraulic conductivity of unsaturated porous media, Water Resour. Res., 12, 513-522, https://doi.org/10.1029/wr012i003p00513, 1976.

Musick, J. T. and Dusek, D. A.: Planting date and water deficit effects on development and yield of irrigated winter wheat, Agron J., 72, 45-52, 1980.

Nimah, M. and Hanks, R.: Model for estimating soil water, plant, and atmospheric interrelations: I. Description and sensitivity, Soil Sci. Soc. Am. J., 37, 522-527, https://doi.org/10.2136/sssaj1973.03615995003700040018x, 1973.

Oroud, I. M.: Climate change impacts on green water fluxes in the Eastern Mediterranean, in: Climate Change and the Sustainable Use of Water Resources, Springer, 3-15, 2012.

Peters, A., Durner, W., and Iden, S. C.: Modified Feddes type stress reduction function for modeling root water uptake: accounting for limited aeration and low water potential, Agr. Water Manage., 185, 126-136, https://doi.org/10.1016/j.agwat.2017.02.010, 2017.

Poorter, H., Niklas, K. J., Reich, P. B., Oleksyn, J., Poot, P., and Mommer, L.: Biomass allocation to leaves, stems and roots: meta-analyses of interspecific variation and environmental control, New Phytol., 193, 30-50, https://doi.org/10.1111/j.14698137.2011.03952.x, 2012.

Rodriguez, D., Ewert, F., Goudriaan, J., Manderscheid, R., Burkart, S., and Weigel, H. J.: Modelling the response of wheat canopy assimilation to atmospheric $\mathrm{CO}_{2}$ concentrations, New Phytol., 150, 337-346, https://doi.org/10.1046/j.14698137.2001.00106.x, 2001.

Schmidt, M.: TERENO Data Discovery Portal - Eifel/Lower Rhine Valley Observatory, available at: http://teodoor.icg.kfa-juelich. de/ibg3searchportal2/index.jsp, last access: 6 October 2014.

Senock, R. S., Ham, J. M., Loughin, T. M., Kimball, B. A., Hunsaker, D. J., Pinter, P. J., Wall, G. W., Garcia, R. L., and LaMorte, R. L.: Sap flow in wheat under free-air $\mathrm{CO}_{2}$ enrichment, Plant Cell Environ., 19, 147-158, https://doi.org/10.1111/j.13653040.1996.tb00236.x, 1996.

Šimůnek, J. and Hopmans, J. W.: Modeling compensated root water and nutrient uptake, Ecol. Model., 220, 505-521, https://doi.org/10.1016/j.ecolmodel.2008.11.004, 2009.

Šimůnek, J., Šejna, M., Saito, H., Sakai, M., and van Genuchten, M.: The HYDRUS-1-D software package for simulating the one-dimensional movement of water, heat and multiple solutes in variably-saturated media, in: HYDRUS Software Series 3, Version 4.17 ed., Department of Environmental Sciences, University of California Riverside, Riverside, California, US, 2013.
Šimůnek, J., van Genuchten, M. T., and Šejna, M.: Recent developments and applications of the HYDRUS computer software packages, Vadose Zone J., 15, https://doi.org/10.2136/vzj2016.04.0033, 2016.

Skaggs, T. H., van Genuchten, M. T., Shouse, P. J., and Poss, J. A.: Macroscopic approaches to root water uptake as a function of water and salinity stress, Agr. Water Manage., 86, 140-149, https://doi.org/10.1016/j.agwat.2006.06.005, 2006.

Steudle, E.: Water uptake by roots: effects of water deficit, J. Exp. Bot., 51, 1531-1542, https://doi.org/10.1093/jexbot/51.350.1531, 2000.

Tardieu, F., Parent, B., Caldeira, C. F., and Welcker, C.: Genetic and physiological controls of growth under water deficit, Plant Physiol., 164, 1628-1635, https://doi.org/10.1104/pp.113.233353, 2014.

Thorup-Kristensen, K., Cortasa, M. S., and Loges, R.: Winter wheat roots grow twice as deep as spring wheat roots, is this important for N uptake and N leaching losses?, Plant Soil, 322, 101-114, https://doi.org/10.1007/s11104-009-9898-z, 2009.

Trillo, N. and Fernandez, R. J.: Wheat plant hydraulic properties under prolonged experimental drought: stronger decline in rootsystem conductance than in leaf area, Plant Soil, 277, 277-284, https://doi.org/10.1007/s11104-005-7493-5, 2005.

Twine, T. E., Kustas, W., Norman, J., Cook, D., Houser, P., Meyers, T., Prueger, J., Starks, P., and Wesely, M.: Correcting eddy-covariance flux underestimates over a grassland, Agr. Forest Meteorol., 103, 279-300, https://doi.org/10.1016/s01681923(00)00123-4, 2000.

Unger, P. W. and Kaspar, T. C.: Soil compaction and root growth a review, Agron J., 86, 759-766, 1994.

Vadez, V.: Root hydraulics: the forgotten side of roots in drought adaptation, Field Crop. Res., 165, 15-24, https://doi.org/10.1016/j.fcr.2014.03.017, 2014.

Van Genuchten, M. T.: A closed-form equation for predicting the hydraulic conductivity of unsaturated soils, Soil Sci. Soc. Am. J., 44, 892-898, 1980.

van Lier, Q. D., van Dam, J. C., Metselaar, K., de Jong, R., and Duijnisveld, W. H. M.: Macroscopic root water uptake distribution using a matric flux potential approach, Vadose Zone J., 7, 1065-1078, https://doi.org/10.2136/vzj2007.0083, 2008.

Vandoorne, B., Beff, L., Lutts, S., and Javaux, M.: Root water uptake dynamics of Cichorium intybus var. sativum under water-limited conditions, Vadose Zone J., 11, https://doi.org/10.2136/vzj2012.0005, 2012.

Vereecken, H., Huisman, J. A., Franssen, H. J. H., Bruggemann, N., Bogena, H. R., Kollet, S., Javaux, M., van der Kruk, J., and Vanderborght, J.: Soil hydrology: recent methodological advances, challenges, and perspectives, Water Resour. Res., 51, 26162633, https://doi.org/10.1002/2014wr016852, 2015.

Vereecken, H., Schnepf, A., Hopmans, J. W., Javaux, M., Or, D., Roose, D. O. T., Vanderborght, J., Young, M. H., Amelung, W., Aitkenhead, M., Allison, S. D., Assouline, S., Baveye, P., Berli, M., Bruggemann, N., Finke, P., Flury, M., Gaiser, T., Govers, G., Ghezzehei, T., Hallett, P., Franssen, H. J. H., Heppell, J., Horn, R., Huisman, J. A., Jacques, D., Jonard, F., Kollet, S., Lafolie, F., Lamorski, K., Leitner, D., McBratney, A., Minasny, B., Montzka, C., Nowak, W., Pachepsky, Y., Padarian, J., Romano, N., Roth, K., Rothfuss, Y., Rowe, E. C., Schwen, A., Šimůnek, J., Tiktak, A., Van Dam, J., van der Zee, S., Vo- 
gel, H. J., Vrugt, J. A., Wohling, T., and Young, I. M.: Modeling soil processes: review, key challenges, and new perspectives, Vadose Zone J., 15, https://doi.org/10.2136/vzj2015.09.0131, 2016.

Walter, A. and Schurr, U.: Dynamics of leaf and root growth: endogenous control versus environmental impact, Ann. Bot., 95, 891-900, https://doi.org/10.1093/aob/mci103, 2005.

Wang, M., Zheng, Q. S., Shen, Q. R., and Guo, S. W.: The critical role of potassium in plant stress response, Int. J. Mol. Sci., 14, 7370-7390, https://doi.org/10.3390/ijms14047370, 2013.

Wells, C. and Birchfield, S.: Rootfly: Software for Minirhizotron Image Analysis, Clemson University, Kingstree, SC, 2009.

Wesseling, J.: Meerjarige simulaties van grondwateronttrekking voor verschillende bodemprofielen, grondwatertrappen en gewassen met het model SWATRE, Wageningen, SC-DLO Report 152, 1991.

Wesselius, J. C. and Brouwer, R.: Influence of water stress on photosynthesis, respiration and leaf growth of Zea mais L., Mededelingen Landbouwhogeschool Wageningen, 72, 1-15, 1972.

White, C. A., Sylvester-Bradley, R., and Berry, P. M.: Root length densities of UK wheat and oilseed rape crops with implications for water capture and yield, J. Exp. Bot., 66, 2293-2303, https://doi.org/10.1093/jxb/erv077, 2015.

Xin-yang, Z. and Yang-ren, W.: Effect of water and nitrogen stresses on correlation among winter wheat organs, 7th International Conference on Computer and Computing Technologies in Agriculture (CCTA), Beijing, China, September 18-20, 2013, 316$325,2013$.
Yang, D., Zhang, T., Zhang, K., Greenwood, D. J., Hammond, J. P., and White, P. J.: An easily implemented agro-hydrological procedure with dynamic root simulation for water transfer in the cropsoil system: validation and application, J. Hydrol., 370, 177-190, https://doi.org/10.1016/j.jhydrol.2009.03.005, 2009.

Yang, J., Hammer, R. D., and Blanchar, R. W.: Minirhizotron quantification of soybean root growth as affected by reduced a horizon in soil, J. Plant Nutr. Soil Sc., 166, 708-711, https://doi.org/10.1002/jpln.200321193, 2003.

Zhang, X. Y., Pei, D., and Chen, S. Y.: Root growth and soil water utilization of winter wheat in the North China Plain, Hydrol. Process, 18, 2275-2287, https://doi.org/10.1002/hyp.5533, 2004.

Zhang, Z., Tian, F., Hu, H., and Yang, P.: A comparison of methods for determining field evapotranspiration: photosynthesis system, sap flow, and eddy covariance, Hydrol. Earth Syst. Sci., 18, 1053-1072, https://doi.org/10.5194/hess-18-1053-2014, 2014.

Zhou, S., Han, Y. Y., Chen, Y. H., Kong, X. Z., and Wang, W.: The involvement of expansins in response to water stress during leaf development in wheat, J. Plant Physiol., 183, 64-74, https://doi.org/10.1016/j.jplph.2015.05.012, 2015. 